\title{
Spatial and temporal variability of winter snow and precipitation days in the western and central Spanish Pyrenees
}

\begin{abstract}
In this study we analysed the spatial distribution of the long-term average and interannual variability of the number of snow days (NSD) and the number of precipitation days (NPD) in winter (DJFM) in the Spanish Pyrenees, using data from 38 meteorological stations for the period 1981-2010. The interannual variability of the NSD and the NPD in winter was related to the frequency of weather types over the Iberian Peninsula. Data from six stations were also used to analyse a longer time period (1961-2013) to confirm the consistency of the results obtained during the main study period (1980-2010).

The results indicated that the NPD is only influenced by the distance to sea whereas the NSD is determined by elevation and distance to the sea. A high frequency of west (W), northwest (NW) and cyclonic (C) weather systems led to a high NPD in winter across the entire study area, whereas the frequency of north (N) weather types was only correlated with the NPD at the most westerly stations. For the NSD there was a gradient from the Western Pyrenees to eastern areas, mainly explained by the frequency of $\mathrm{N}$ weather types in the former area, and high frequencies of $\mathrm{NW}$ and $\mathrm{W}$ weather types associated with the latter. For most stations there was no significant trend found in the NPD or the NSD for the 1981-2010 period. However, a slight decrease was found for stations strongly correlated with $\mathrm{NW}$ weather types, and a slight increase was found for stations strongly correlated with the $\mathrm{C}$ weather type, which was related to a decreasing (increasing) frequency of $\mathrm{NW}$ (C) weather types during the same period. Analysis of the 1961-2013 and 1971-2000 time slices using a smaller subset of stations revealed a similar relationship between weather types and the NSD. This indicates that the 1981-2010 period is sufficiently representative to describe the relationship of the NSD and the NPD to weather type frequency. However, the study period chosen can markedly influence the trends observed, as the results showed a statistically significant decrease in the NSD for the 1971-2000 period, but no significant trends for the 1961-2013 and 1980-2010 periods.
\end{abstract}

KEY WORDS snow days; winter precipitation days; weather types; temporal trends; Pyrenees; Spain

Received 25 September 2013; Revised 27 January 2014; Accepted 7 February 2014

\section{Introduction}

Study of the spatial and temporal variability of the snowpack is of great interest because this variability controls the ecology and hydrological response of mountainous areas and cold regions (Barnett et al., 2005; Mellander et al., 2007; Jonas et al., 2008a, 2008b), and affects economic activities including winter tourism, hydropower generation and water supply for agriculture (Beniston, 2003; Barnett et al., 2005; Lasanta et al., 2007; Uhlmann et al., 2009). Furthermore, the interannual variability of snowpack and snow cover is directly related to temperature and precipitation in the preceding months, and is thus a useful indicator of climate variability and change in areas where climate data of good quality are generally lacking (Wash, 1995; Nesje and Dahl, 2000; Carrivick and Brewer, 2004).

* Correspondence to: S. T. Buisan, Spanish Meteorological State Agency, Paseo del Canal 17, Zaragoza 50007, Spain.

E-mail: sbuisans@aemet.es
The snowpack plays a major role in the hydrology of the Pyrenees region (López-Moreno and García-Ruiz, 2004), and determines the potential of Pyrenean reservoirs to supply water during the dry season (López-Moreno et al., 2008a). A decrease in snow accumulation occurred in this region during the second half of the 20th century (López-Moreno, 2005), and this has been partially attributed to changes in the frequency of weather types over the Iberian Peninsula (López-Moreno and Vicente-Serrano, 2007). However, the effects of these changes can be spatially variable in the Iberian Peninsula, because interactions between topography and exposure to different air masses lead to marked differences in the response of neighbouring areas to synoptic or hemispheric circulation patterns (Corte-Real et al., 1998; Goodess and Jones, 2002; Esteban et al., 2005; Vicente-Serrano and López-Moreno, 2006). Snowpack simulations according to climate projections from various regional climate models (RCMs) indicate an acceleration of the observed trends during coming decades, which will have profound effects on areas at low elevations (López-Moreno et al., 
1 2008b; López-Moreno et al., 2009; Maris et al., 2009). 2 Despite numerous studies of changes in the snowpack 3 in the Pyrenees and other Spanish mountains, studies of 4 other snow-related variables including the number of days 5 on which snowfall is recorded have not been undertaken. 6 The number of snow days (NSD) is an important indicator 7 of climate variability and change, because it provides 8 detailed information concerning the number of precipita9 tion days (NPD) when the temperature is below freezing. 10 The annual NSD and variability also has important impli11 cations for management of the Pyrenees area, especially in

populated areas where the NSD is on average very low and winter preparedness is limited. Snowfall in inhabited areas disrupts transport, increases the number of traffic accidents and injured pedestrians and affects the normal functioning of infrastructure (Vajda et al., 2012). From an economic point of view the proper maintenance of roads and communication services is expensive, and can affect the income from ski resorts and tourism in mountain areas, with potentially negative effects on local economies ( $\bullet$ Pons et al., 2003; Scott and McBoyle, 2007; Gonseth, 2013).

The relatively few studies considering snow days is explained by the poor reliability of the long-term data series for this variable, as it is dependent on direct intra-day observations of precipitation falling as snow. In •western United States (Knowles et al., 2006) a shift from snowfall total precipitation to rainfall total precipitation detected during the 1949-2005 period attributed to a temperature increase on wet days and which mainly affected the sites, which had mean temperatures warm enough that moderate warming was sufficient to impact the precipitation form.

In the Swiss Alps a decrease in the number of snowfalls has been detected, and associated with precipitation falling as rain rather than snow. This trend is more significant at mid- and low elevations, although the magnitude of change is very dependent on the study period (Laternser and Schneebeli, 2003; Serquet et al., 2011).A recently published article (Scherrer et al., 2013) shows large decadal variability with phases of low and high values for the snowfall events.

Regarding the French Pyrenees, Maris et al. (2009) due to the lack of a sufficient amount of directly observed long-term snow data had to use climate reanalysis for the 1958-2008 periods using the SAFRAN and CROCUS models. This work shows that precipitation trends are not significant, making it hard to detect clear tendencies in French Pyrenees.

Pons et al. (2010) used data from 34 stations to analyse the evolution of snow days throughout northern Spain during the period 1957-2002. The NSD showed a negative trend from the mid-1970s, as a consequence of increasing temperature and decreasing precipitation at some stations at high elevation. However, this study only included three stations in the western Pyrenees, and the most important mountain sector of Spain in terms of snow accumulation and duration was not included.

In this study we analysed the spatial variability and trends in the NSD and the NPD in the western and central Spanish Pyrenees. We used a newly created dataset derived from a dense network of meteorological stations where these indices have been regularly recorded. The objectives of the study were: (1) to identify the main geographical factors leading to the spatial variability of the NSD and the NPD; (2) to analyse the interannual evolution and observed trends in the NSD and the NPD and (3) to relate variability to atmospheric circulation at the regional scale, using an objective weather type classification.

\section{The study area}

The study area encompasses the central and western Spanish Pyrenees (Figure 1). The eastern Spanish Pyrenees was excluded because it has very few stations providing long climatic series. The elevation in this region increases from west to east, with maximum peak heights ranging from $300 \mathrm{~m}$ to slightly more than $3000 \mathrm{~m}$ a.s.l. However, the stations used in this study are generally located in towns and villages, and all are located at less than $1500 \mathrm{~m}$ a.s.l.

Precipitation varies following north-south and west-east gradients, based on the elevation and the transition from Atlantic to Mediterranean climate characteristics (García--Ruiz et al., 2001). The average elevation gradually increases from west to east. The topographic heterogeneity of the region partially explains the large spatial variability of annual precipitation. Stations at mid-elevations (approximately $800 \mathrm{ma}$ a.s.l.) in western areas receive more precipitation in winter than stations at the same elevation in central areas.

Temperatures are determined by elevation. Del Barrio

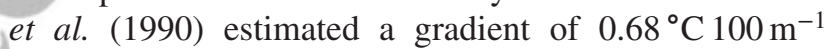
of altitudinal increase. From November to April the $0{ }^{\circ} \mathrm{C}$ isotherm is at approximately $1600-1700 \mathrm{~m}$ a.s.l. (García-Ruiz et al., 1986), representing the level above which accumulated snow remains for extended periods. Our study focused on areas below $1500 \mathrm{~m}$ a.s.l., where the population density is greater, and consequently where snowfall causes more problems. Although snowfall in these areas has effects at higher elevations, these were not considered in the study because long-term climate series for these elevations are not available.

\section{Data and methods}

\subsection{Climate data}

Data on snow and precipitation in the area have been recorded at meteorological stations managed by the Spanish Meteorological State Agency (AEMET). The main study period was from 1981 to 2010, and was restricted to the winter period from December to March (DJFM). This period was selected because: (1) it is the last 30 years climate standard reference period of time (normal period) as recommended by the World Meteorological Organization (WMO, 1989) and (2) it contains the largest number of stations having long climate series. However, for six stations it was possible to obtain series covering the period 1961-2013, enabling analysis of the study results in a wider temporal context. 


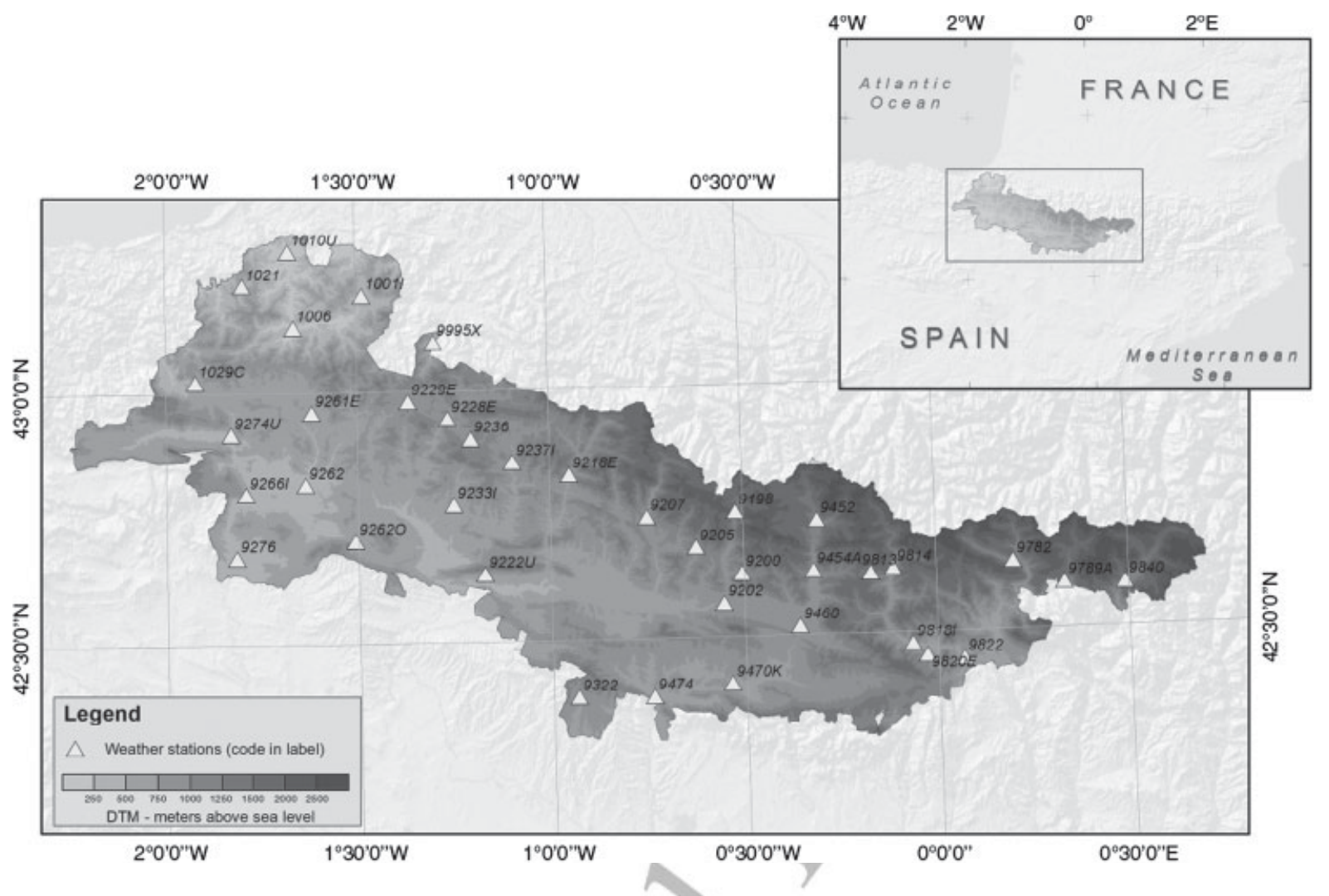

Figure 1. Study area and location of weather stations. This figure is available in colour online at wileyonlinelibrary.com/journal/joc

A snowfall event is recorded on the database if it occurred within a 24-h period, day or night, (from 06:00 UTC to 06:00 UTC), even if it does not cover the ground. Precipitation events were based on a threshold of $0.1 \mathrm{~mm}$ total precipitation. This threshold was used in order to account for weak snowfalls with low precipitation rates $(<1 \mathrm{~mm})$ and recorded also on the database as snow day. The precipitation database did not show too many cases below $1 \mathrm{~mm}$, around $5 \%$ on average. If liquid and solid forms of precipitation have been reported on the station on the same day, both events are recorded on the database as a precipitation and snow day. The database did not include the amount of precipitation associated with each event. All these data were manually checked and corrected by AEMET staff prior to be recorded in the AEMET database. The original database contained data from more than 100 stations. The criteria for selection were the data quality (previous knowledge of climate series and observer) and that the data availability exceeded $90 \%$ for each series for the study period. Missing data of a particular station were filled by means of linear regression using neighbouring stations that exhibited a high coefficient of correlation $(r>0.9)$ with the candidate series and located $<10 \mathrm{~km}$ distant and at a comparable elevation (within $200 \mathrm{~m}$ ). In many cases the hand written manuscript as recorded by the observer was verified on AEMET climatological archive and some mistakes were found and corrected. Using this procedure, the percentage of missing data that were completed was less than $7 \%$ of the all database.
The final database contained 38 complete series covering the entire study period (Table 1). The elevation of the selected stations ranged from 45 to $1422 \mathrm{~m}$ a.s.l., and the stations were representative of low- and mid-elevation sectors of the western and central Spanish Pyrenees. The distances of the stations from the Atlantic Ocean ranged from 17 to $207 \mathrm{~km}$.

To separate the effects of station elevation and distance to the ocean, which was necessary to explain the spatial variability of the long-term average and the interannual variability of the distribution of snowfall and precipitation days, we used stepwise regression models to facilitate identification of the significant predictors. The beta coefficients of the regressions were used to compare the relative weight of the predictors in explaining the long-term average and the interannual variability of snowfall and precipitation days.

\subsection{Weather type classification}

Daily weather types over the Iberian Peninsula were obtained using the objective weather typing system of Jenkinson and Collison (1977), which is based on the Lamb types Lamb and Peppler (1987) - The method requires information on the daily sea level pressure at the 16 points (at $5^{\circ}$ resolution) that comprise the Iberian Peninsula (López-Moreno and Vicente-Serrano, 2007). Sea level pressure data were obtained from the - NCEP database (http://www.esrl.noaa.gov/). The Jenkinson and Collison method (described by Jones et al., 1993) has been successfully used for daily weather type classification in the 
Table 1. List of analysed stations and their elevation, distance to the sea and mean NSD and NPD during winter (DEFM) for the 1981-2010 period.

\begin{tabular}{|c|c|c|c|c|c|}
\hline Station code & Name & Elevation (m) & Distance to sea $(\mathrm{km})$ & NSD & NPD \\
\hline 9236 & Abaurrea Alta & 1047 & 73 & 20.7 & 54.4 \\
\hline 9205 & Aisa De Jaca & 1040 & 125 & 13.4 & 38.4 \\
\hline $9228 \mathrm{E}$ & Arive & 700 & 66 & 9.9 & 52.0 \\
\hline $1001 \mathrm{I}$ & Arizcun De Baztan & 257 & 36 & 4.4 & 56.9 \\
\hline 1021 & Articutza & 305 & 17 & 6.0 & 64.9 \\
\hline $1029 \mathrm{C}$ & Azpiroz-Casa Cia & 545 & 32 & 9.5 & 64.4 \\
\hline 9200 & Bescos De Garcipollera & 920 & 136 & 11.1 & 37.6 \\
\hline 9322 & Biel & 760 & 132 & 6.7 & 34.7 \\
\hline $9454 \mathrm{~A}$ & Biescas (Central II) & 855 & 148 & 10.4 & 37.9 \\
\hline 9822 & Boltaña & 643 & 186 & 3.5 & 24.8 \\
\hline 9198 & Canfranc Los Ara/Ones & 1160 & 127 & 19.6 & 45.6 \\
\hline 9452 & El Pueyo De Jaca & 1091 & 143 & 15.5 & 34.8 \\
\hline 9233I & Eparoz & 605 & 82 & 5.7 & 42.9 \\
\hline 9840 & Eriste (Central) & 1100 & 207 & 10.6 & 26.0 \\
\hline 9237I & Esparza De Salazar & 687 & 83 & 16.8 & 51.1 \\
\hline $9229 \mathrm{E}$ & Espinal-Auzperri & 870 & 59 & 15.8 & 52.5 \\
\hline $9789 \mathrm{~A}$ & Gistain & 1422 & 196 & 17.5 & 31.1 \\
\hline 9207 & Hecho & 855 & 112 & 13.0 & 42.5 \\
\hline $9274 \mathrm{U}$ & Irurzun & 455 & 45 & 8.8 & 50.0 \\
\hline 9202 & Jaca & 800 & 137 & 9.9 & 38.0 \\
\hline $9470 \mathrm{~K}$ & Javierrelatre & 709 & 151 & 7.3 & 29.5 \\
\hline 9474 & La Peña (Embalse) & 589 & 142 & 3.0 & 28.1 \\
\hline $9222 \mathrm{U}$ & Leyre Monasterio & 756 & 98 & 10.0 & 41.8 \\
\hline 9813 & Linas De Broto & 1333 & 159 & 9.6 & 22.6 \\
\hline $9262 \mathrm{O}$ & Monreal & 545 & 77 & 6.4 & 43.6 \\
\hline $9261 \mathrm{E}$ & Olague & 545 & 48 & 9.1 & 51.0 \\
\hline $9266 \mathrm{I}$ & Otazu & 387 & 59 & 3.5 & 39.7 \\
\hline 9262 & Pamplona Observatorio & 442 & 61 & 7.7 & 50.9 \\
\hline 9782 & Pineta (Presa) & 1150 & 184 & 10.9 & 30.5 \\
\hline 9276 & Puente La Reina & 346 & 72 & 4.6 & 42.9 \\
\hline 9460 & Sabiñanigo & 790 & 153 & 6.4 & 32.0 \\
\hline $9820 \mathrm{E}$ & San Felices & 812 & 179 & 5.9 & 22.5 \\
\hline $9818 \mathrm{I}$ & Santa Olaria De Ara & 740 & 175 & 5.9 & 26.9 \\
\hline 1006 & Santesteban & 131 & 31 & 3.1 & 58.4 \\
\hline 9814 & Torla & 1053 & 162 & 12.4 & 32.7 \\
\hline $9218 \mathrm{E}$ & Urzainqui & 717 & 94 & 12.3 & 52.5 \\
\hline $9995 X$ & Valcarlos & 320 & 54 & 5.0 & 61.5 \\
\hline $1010 \mathrm{U}$ & Vera De Bidasoa & 45 & 17 & 2.5 & 62.7 \\
\hline
\end{tabular}

Iberian Peninsula, with particularly good results during winter (Goodess and Palutikof, 1998; Spellman 2000). The method discriminates each day among 26 possible weather types: anticyclonic (A); cyclonic (C); eight directional weather types (N, NE, E, SE, S, SW, W and NW); and types that are hybrids of cyclonic, anticyclonic and directional types $(\mathrm{CN}, \mathrm{CNE}, \mathrm{CE}, \mathrm{CSE}, \mathrm{CS}, \mathrm{CSW}, \mathrm{CW}$, CNW, AN, ANE, AE, ASE, AS, ASW, AW and ANW). To simplify the interpretation of the results, the 26 weather types were aggregated into 10 types by elimination of the hybrid types, following the approach of Jones et al. (1993) and Trigo and Da Camara (2000). When a hybrid type was encountered, a value of 0.5 was added to the frequency series for the relevant cyclonic (C) or anticyclonic (A) type, and 0.5 was added to the corresponding directional type (N: north, NE: northeast, E: east, SE: southeast, S: south, SW: southwest, W: west and NW: northwest). The number of days for each synoptic situation observed during winter (December to March) was considered in analysing the relationships among weather types and the snowfall series.

\section{Results 99}

4.1. Snowfall and precipitation days climatology 100

101

Table 1 shows that the long-term average NPD ranged 102 from 22 to 65, while for the NSD the range was 3-4 days 103 per year to almost 21 days. Figure 2 shows the contour 104 plot relating the long-term average and the coefficient of 105 variation of precipitation days to elevation and distance 106 to the sea, and Table 2 shows the correlation coefficients 107 of the NSD and the NPD with elevation and distance to 108 the sea. The NPD decreased with distance to the Atlantic 109 Ocean $(r=-0.91)$ and decreased with increasing elevation 110 $(r=-0.61)$; elevation increases towards the east, whereas 111 precipitation gradually decreases in this direction. Stations 112 close to the sea $(<50 \mathrm{~km})$, and thus at lower elevation, 113 accounted for the greatest NPD, and this factor had a clear 114 influence on the correlation results. It is noteworthy that 115 the stations close to the sea accounted for at least twice as 116 many precipitation days relative to those $100 \mathrm{~km}$ or more 117 from the sea. The interannual variability was greater at 118 
2

3

4

5

6

7

8

9

10

11

12

13

14

15

16

17

18

19

20

21

22

23

24

25

26

27

28

AQ529

30

31

32

33

34

35

36

37

38

39

40

41

42

43

44

45

46

47

48

49

50

51

52

53

54

55

56

57

58

59
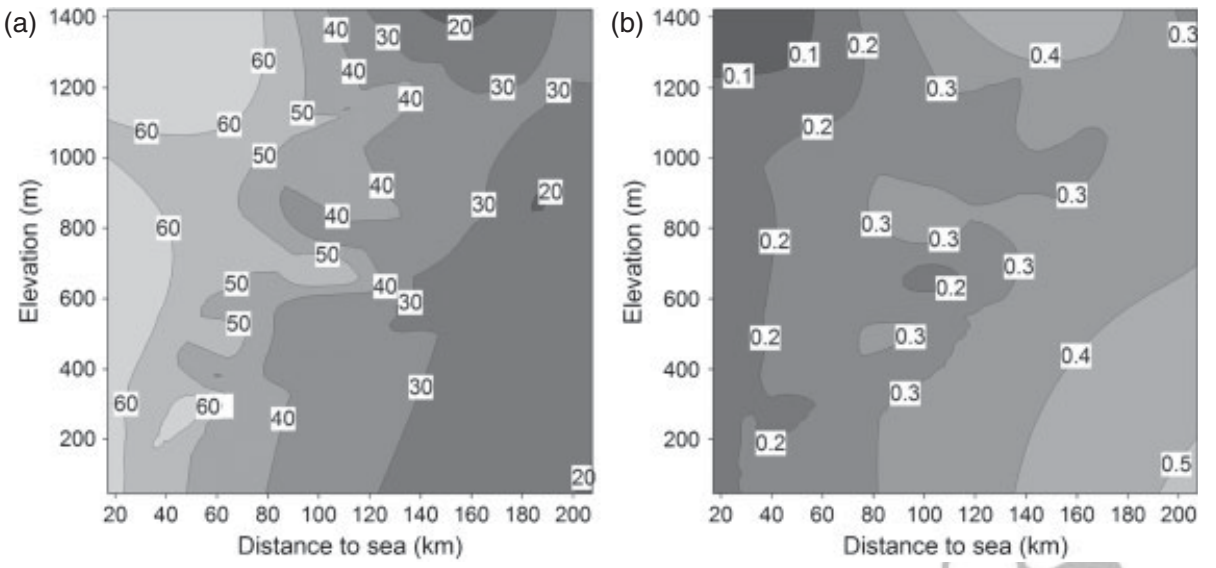

60

61

62

63

64

65

66

67

68

69

70

71

72

73

74

Figure 2. (a) Relationship of the NPD (long-term average) to elevation (m) and distance to the Atlantic Ocean (km). (b) Relationship of the interannual coefficient of variation for the NPD to elevation $(\mathrm{m})$ and distance to the Atlantic Ocean $(\mathrm{km})$.

Table 2. Pearson's correlation coefficients and explanatory variables and coefficients resulting from stepwise multiple linear regressions.

\begin{tabular}{|c|c|c|c|c|c|c|c|c|}
\hline & \multicolumn{2}{|c|}{ Correlations } & \multicolumn{6}{|c|}{ Multiple linear regression } \\
\hline & \multirow[b]{2}{*}{ E } & \multirow[b]{2}{*}{$D$} & \multicolumn{3}{|c|}{ Standardized coefficients } & \multicolumn{3}{|c|}{ Beta coefficients } \\
\hline & & & Constant & $E$ & $D$ & $R^{2}$ & $E$ & $D$ \\
\hline NSD & $0.72 * *$ & 0.21 & 2.49 & 0.02 & -0.67 & 0.79 & 1.31 & -0.77 \\
\hline NSD - coefficient of variation & $-0.84 * *$ & $-0.48 * *$ & 0.96 & -0.01 & 0.01 & 0.76 & -1.12 & 0.36 \\
\hline NPD & $-0.61 * *$ & $-0.91 * *$ & 64.3 & $\mathrm{x}$ & -0.20 & 0.84 & $\mathrm{x}$ & -0.91 \\
\hline NPD - coefficient of variation & $0.56 * *$ & $0.85^{* *}$ & 0.18 & $\mathrm{x}$ & 0.01 & 0.73 & $\mathrm{x}$ & 0.85 \\
\hline
\end{tabular}

$E \bullet$ denotes elevation (m) and $D$ denotes distance to the sea (km). * $\alpha<0.05 ; * * \alpha<0.01$.

high elevation stations $(r=0.56)$ and those more distant from the ocean $(r=-0.85)$. Figure 3 shows a contour plot relating the long-term average and the coefficient of yariation for the NSD with elevation and distance to the sea. The trend in the NSD was opposite to that for the NPD, as it decreased at lower elevation $(r=0.72)$ and increased slightly, but not significantly, with greater distance from the ocean $(r=0.21)$. This was the result of multicolinearity between elevation and distance to the ocean. Despite this strong linear relationship, some stations located at moderate elevations (approximately $1000 \mathrm{~m}$ a.s.l.) had the highest NSD in the study area; these stations are located relatively close to the Atlantic Ocean. The interannual variability was greater for the NSD than the NPD, and it decreased linearly with elevation $(r=-0.84)$ and distance to the ocean $(r=-0.48)$.

To assess the effect of elevation and distance to the ocean in explaining the NPD and the NSD, we conducted four separate stepwise multiple linear regressions using the long-term average and the coefficients of variation for the NPD and the NSD as dependent variables, and elevation and distance to the sea as independent variables. The coefficients, explained variance and beta coefficients obtained for each regression are shown in Table 2.

A high percentage of the variance in the long-term average $(79 \%)$ and the coefficient of variation $(76 \%)$ for the NPD was explained by distance to the Atlantic Ocean. Elevation was not included in the model, which confirmed the occurrence of multicolinearity between elevation and distance to the ocean. However, models explaining the spatial distribution of the long-term average and interannual variability of the NSD include both elevation and distance to the ocean as predictors; 79 and $76 \%$ of the variance shown by the spatial distribution of NSD and its interannual variability was explained by the models. If distance to ocean was not included in the models, the explained variance was 53 and $70 \%$ for the average and coefficient of variation of the NSD, respectively. The beta coefficients also indicated the importance of the contribution of distance to the ocean $(-0.77$ and 0.36$)$ and elevation $(1.31$ and -1.12 ) as predictors in the two models explaining the mean and interannual variability of the NSD.

\subsection{Relationship between weather types and climate} variables

Table 3 shows the frequency of occurrence of the various weather types during winter (December to March) over the Iberian Peninsula. During the study period the anticyclone weather type dominated, with a frequency of approximately $35 \%$ (Table 3 ). The cyclonic weather type occurred on $11 \%$ of the days. The NW and $\mathrm{N}$ weather types had frequencies of $8-10 \%$, and the remaining types (NE, SE, S, $\mathrm{SW}, \mathrm{W}$ and $\mathrm{E}$ ) ranged from 4 to $<8 \%$.

Figure 4 shows that in any winter the occurrence of 116 certain weather types exerted a clear influence on the NPD 117 and the NSD, and the NPD/NSD ratio. Figure 4(a) shows 118 
(a)

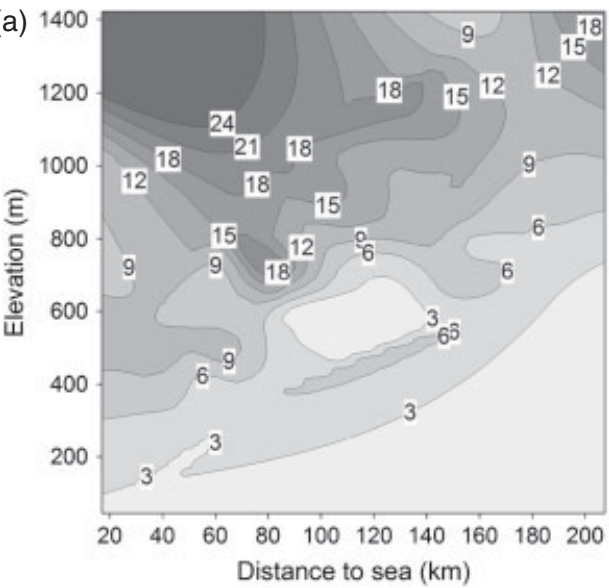

(b)

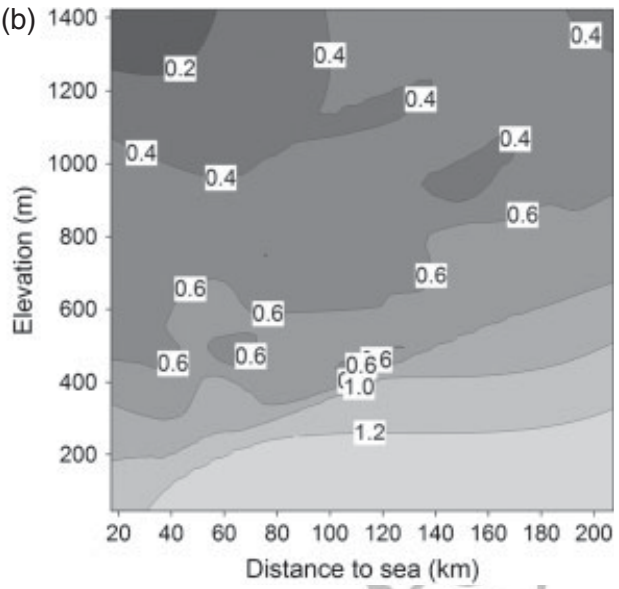

60

61

62

63

64

65

66

67

68

69

70

71

72

73

74

75

Figure 4. Box-plots showing the variability among stations in the correlation between the interannual occurrence of weather types and the NPD (a), 108 the NSD (b) and the NSD/NPD ratio (c). The central line indicates the mean, the boxes are the 75 th and 25 th percentiles, and the bars indicate the 109 90th and 10th percentiles.

that a high frequency of C, N, SW, W and NW weather types led to a high NPD. The W and NW weather types were characterized by a low dispersion in the correlation values, indicating that these atmospheric patterns produce precipitation over the entire study area. The $\mathrm{C}$ type showed rather low dispersion but clearly included outliers, while the SW and $\mathrm{N}$ types showed higher dispersion values, indicating that they had contrasting effects on the NPD across the study area. Winters with more frequent A, E and SE types were characterized by a lower NPD.

Figure 4(b) shows that the frequency of C, N, W and 115 NW weather types was positively correlated with the NSD. 116 However, the high dispersion evident in the box-plots 117 suggests that the frequency of each weather type had 118 


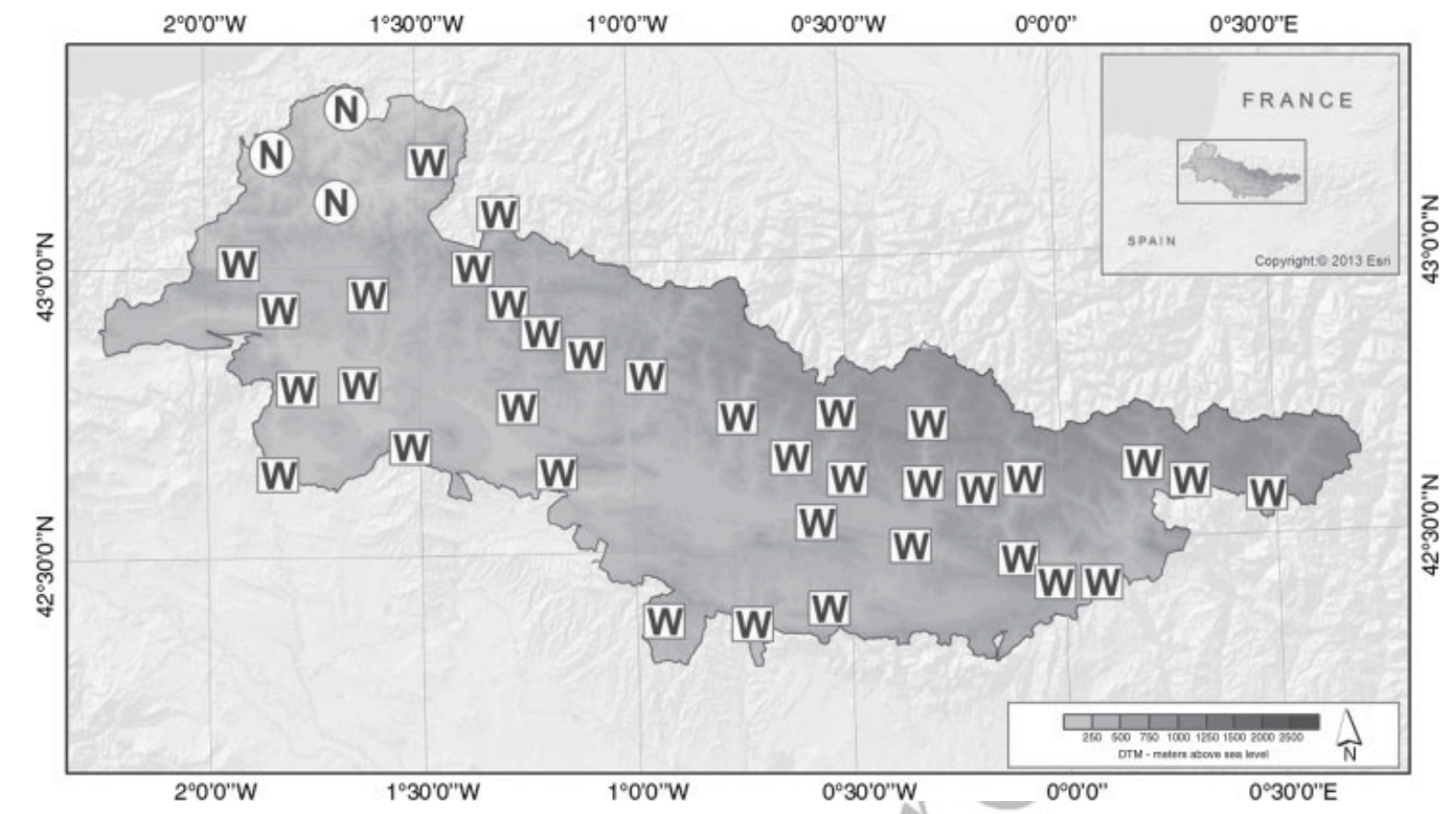

Figure 5. Weather types showing the greatest positive correlation with the NPD per station. This figure is available in colour online at wileyonlinelibrary.com/journal/joc

different effects at the stations in the study area. The SW weather type did not correlate with the NSD, in clear contrast to its correlation with the NPD. A high frequency of anticyclonic days led to a low NSD. Weather types with an easterly component ( $\mathrm{E}$ and $\mathrm{SE}$ ) were associated with a low NSD, but this was not as obvious as the very negative coefficients for the NPD.

The NSD/NPD ratio (Figure 4(c)) clearly increased with northerly flows, and was greater in association with flows from the north and the east (N, NE, E and NW). The $\mathrm{N}$ weather type exhibited lower dispersion among stations, while the NW type showed very large dispersion.

Figure 5 shows the weather type most strongly correlated with the NPD at each station. All these correlations were $>0.5$ and statistically significant $(\alpha<0.01)$. The NDP at most of the stations was most highly correlated with the annual frequency of $\mathrm{W}$ weather types; for three stations, located in the northwest of the study area, the correlation with $\mathrm{N}$ weather types was higher.

Figure 6 shows the relationships between the value of correlation of the NPD and the frequency of W, N, NW and $C$ types with elevation and distance to the sea. The latter two did not show the strongest correlation at any station (Figure 5), but had a strongly positive correlation with the NPD (Figure 4). Table 4 shows that the $\mathrm{N}$ and NW weather types were negatively correlated with distance to the sea, because stations far from the sea are more blocked from humid flows. In the case of the $\mathrm{N}$ types the fit was almost linear $(r=-0.91)$, and was very strong in the case of NW types $(r=-0.68)$. Similar correlations were evident in relation to elevation, because it increases with distance from the sea. Considering the values from which significant correlations $(\alpha<0.05)$ were obtained (dashed line in Figure 6) it can be inferred that $\mathrm{N}$ weather types mainly caused precipitation at stations $<120 \mathrm{~km}$ from the sea. The $\mathrm{W}$ and $\mathrm{C}$ weather types were positively correlated $(r=0.55)$ and $(r=0.74)$, respectively, with distance to the sea because these flows were able to affect all stations, including those at distance from the sea; the Pearson's correlation coefficients were therefore high and positive for all stations. However, the NPD at stations furthest from the sea show clearly a higher positive response to these types being also positively correlated with elevation, because elevation increases far from sea on eastward direction they were positively correlated with elevation.

Figure 7 shows the relationships between the NSD and the weather type most strongly correlated for each station. All correlations were significant $(\alpha<0.05)$ for all stations, and strongest for stations at higher elevations (Figure 8).

The NSD in the western area, and at mid-to-high elevation stations, was mainly associated with the $\mathrm{N}$ weather type. In the central part of the Pyrenees the strongest correlation was with the NW weather type. The W weather type was strongly correlated at only two stations (Gistain and Torla), which are located at the highest elevations and are in a valley open to westerly influences. The $\mathrm{C}$ weather type was characteristic of stations at low elevations near the sea, or at stations distant from both the sea and the highest areas of the Pyrenees.

To investigate the relationship between NSD and 110 weather type we compared the Pearson's correlation 111 coefficients for each relevant weather type (N, NW, W 112 and $\mathrm{C}$ ) producing snowfall with elevation and distance to 113 the sea. Figure 8 and Table 4 show that the NW and W 114 weather types showed a positive and strong correlation 115 $(r=0.86)$ and $(r=0.81)$, respectively, with elevation being 116 the main factor determining whether snowfall was likely 117 to occur. Consequently, stations at high elevations that 118 
(a)
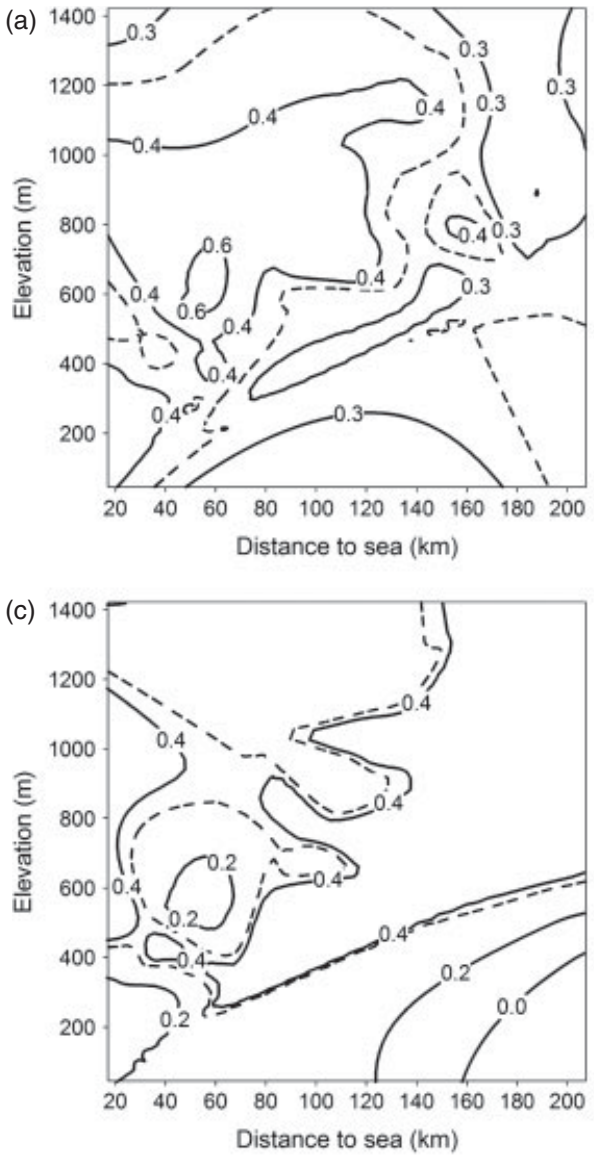

(b) $1 4 0 0 \longdiv { 0 . 6 - 0 . 6 } \quad \succ _ { 0 . 7 }$
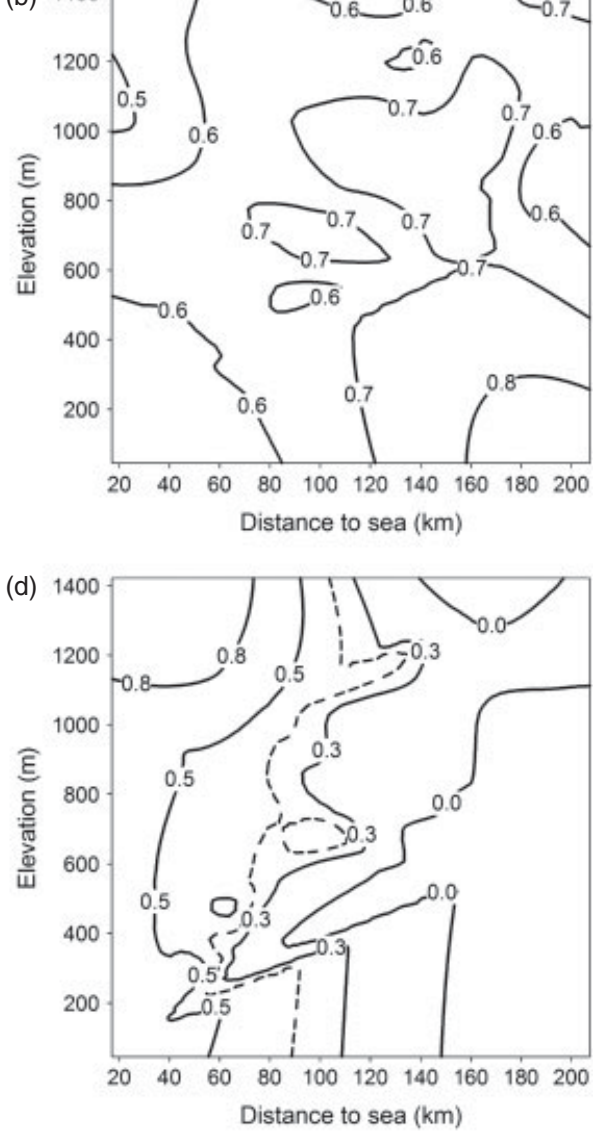

60

Figure 6. Relationships between the value of the correlations of the NPD and the frequency of weather types with elevation and the distance to the sea. The dashed lines show the limit of significance of the Pearson's correlation coefficient $(\alpha<0.05$ ). Weather types: (a) NW, (b) W, (c) $\mathrm{C}$ and $(\mathrm{d}) \mathrm{N}$.

Table 4. Pearson's correlation coefficients between weather types (N, NW, W, C) and the NSD and the NPD with elevation and distance to the sea.

\begin{tabular}{|c|c|c|c|c|}
\hline \multirow[b]{2}{*}{ Weather type } & \multicolumn{2}{|c|}{ Snow days (NSD) } & \multicolumn{2}{|c|}{ Precipitation days (NPD) } \\
\hline & Elevation (m) & nce to sea $(\mathrm{km})$ & Elevation (m) & Distance to sea $(\mathrm{km})$ \\
\hline NW & $0.86 * *$ & $0.72 * *$ & $-0.37 *$ & $-0.68 * *$ \\
\hline W & 0.81 & $0.74 * *$ & $0.58 * *$ & $0.55 * *$ \\
\hline C & $-0.38 *$ & -0.30 & $0.51 * *$ & $0.74 * *$ \\
\hline $\mathrm{N}$ & -0.01 & -0.31 & $-0.55 * *$ & $-0.91 * *$ \\
\hline
\end{tabular}

$* \alpha<0.05 ; * * \alpha<0.01$.

were strongly correlated with NW weather type were also strongly correlated with the $\mathrm{W}$ weather type. The difference was because westerly flows (W) are associated with higher temperatures than the northwesterly flows (NW). For the NW type, 22 stations had correlation coefficients $>0.5$, while for the $\mathrm{W}$ type this occurred for only three stations. The $\mathrm{C}$ weather type had a significant negative correlation $(r=-0.38)$ with elevation, and also a negative (but not significant) correlation with distance to the sea. In addition, these stations receive less snow on average than the others, and although significant the correlation coefficients were very low. For the $\mathrm{N}$ weather type, ten stations in the western area had correlations $>0.5$. This weather type was associated with cold air over the entire area and did not appear to be related to elevation, and distance to the sea was the major factor related to snowfall 104 occurrence. For the weather types NW and W for which 105 significant correlations $(\alpha<0.05)$ were found (dashed line 106 in Figure 8), the rain-snow line was estimated to be at 107 approximately $700 \mathrm{~m}$ for the NW type, while for the W 108 type it was estimated to be at approximately $1100 \mathrm{~m}$ for 109 the stations $<40 \mathrm{~km}$ from the sea. This decreased eastward 110 to approximately $800 \mathrm{~m}$ for the stations $100-180 \mathrm{~km}$ from 111

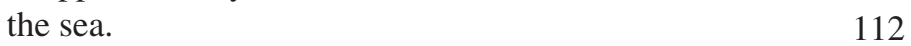

4.3. Trends in the NSD and the NDP: relationship with 113 $\begin{array}{ll}\text { variability in atmospheric circulation } & 114 \\ & 115\end{array}$

To detect significant trends, temporal series were tested 116 against a linear time evolution (1981-2010) using the 117 nonparametric Spearman's rank correlation statistic test. 118 

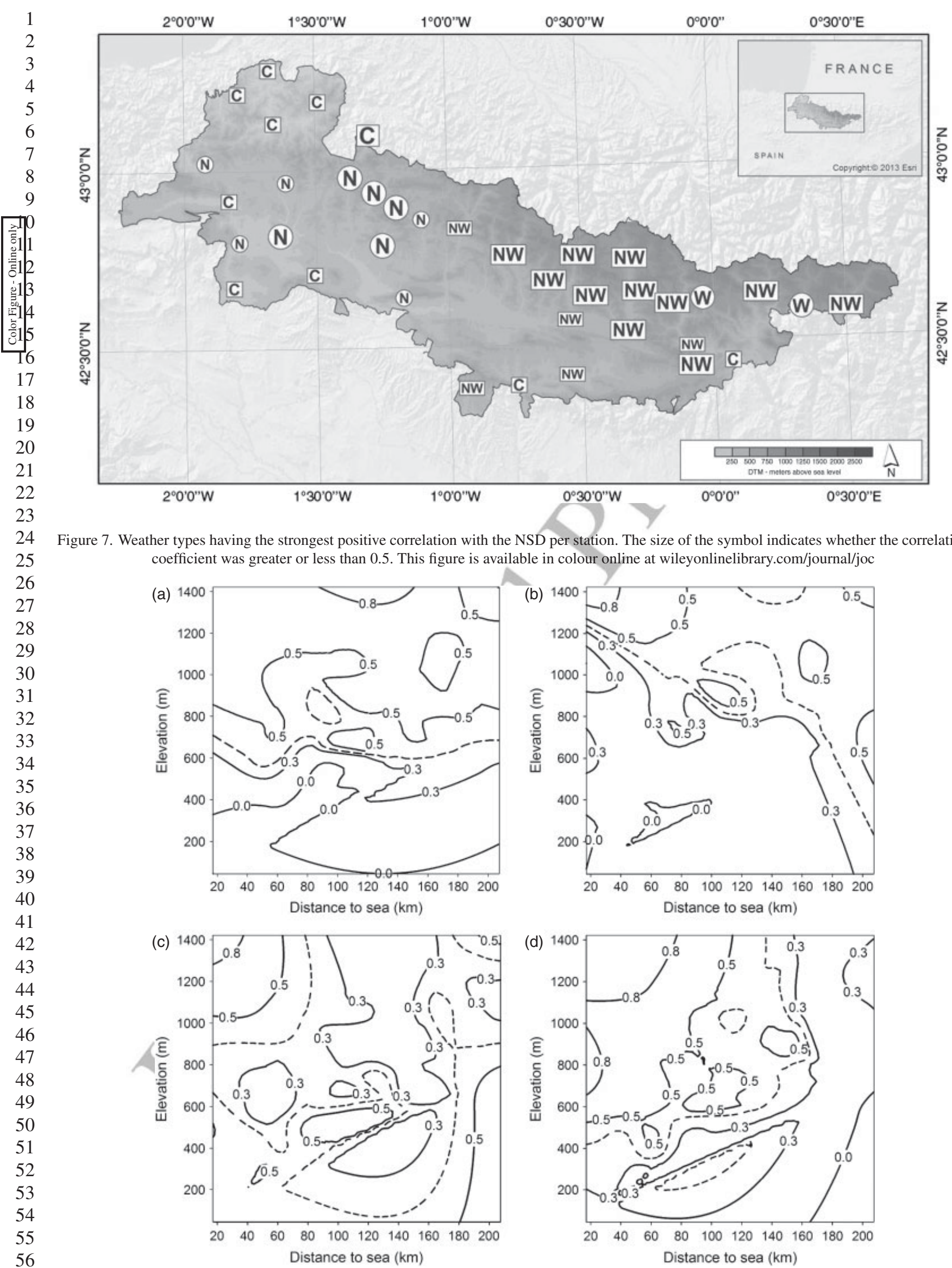

101

102

103

104

105

106

107

108

109

111

112

113

Figure 8. Relationship of the value of the correlation for the NSD and weather type with elevation and distance to the sea. The dashed line shows 117 the limit of significance of the Pearson's correlation coefficient $(\alpha<0.05$ ). Weather types: (a) NW, (b) W, (c) C and (d) N. 


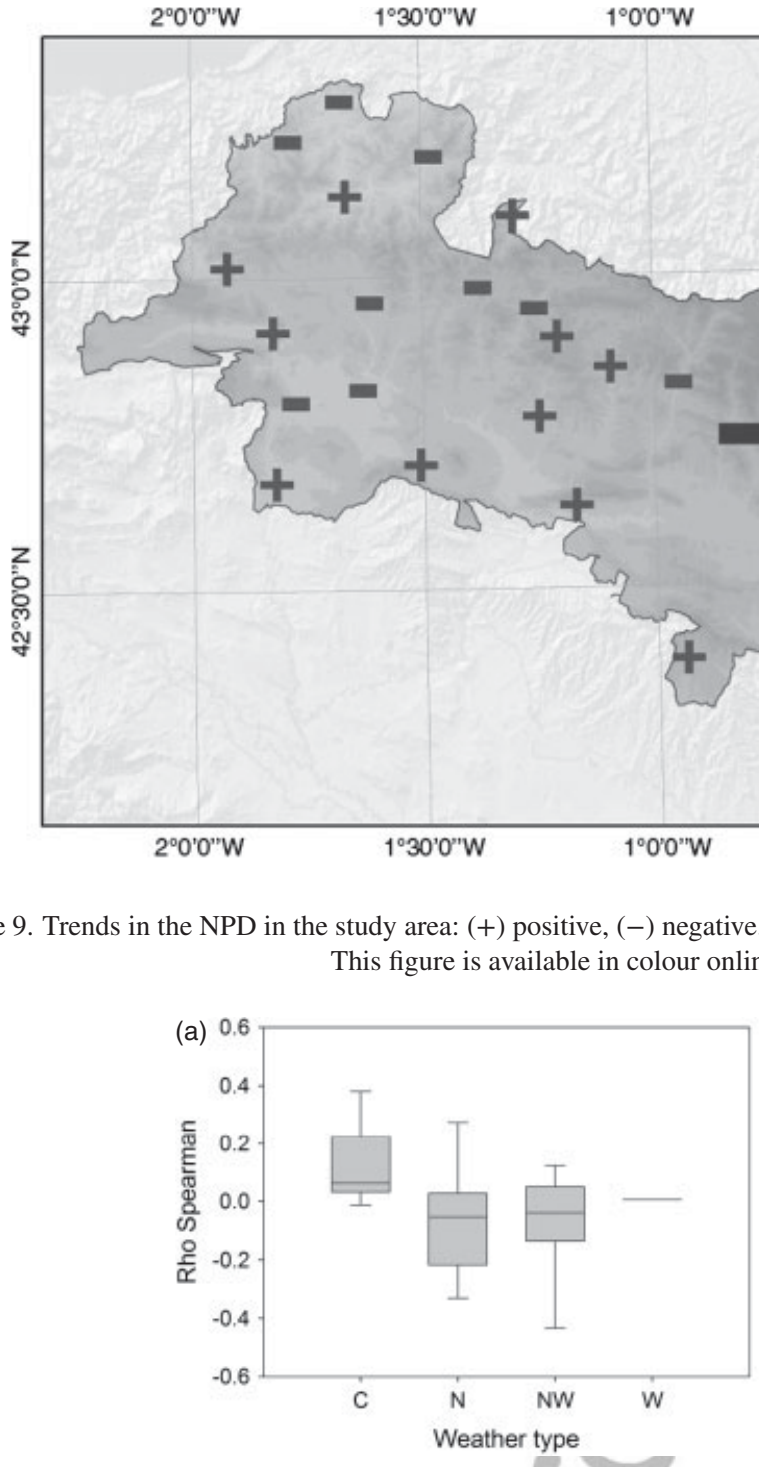

$0^{\circ} 30^{\prime} 0^{\prime \prime} \mathrm{W}$

$0^{\circ} 0^{\prime} 0^{\prime \prime}$ $0^{\circ} 30^{\prime} 0^{\prime \prime} \mathrm{E}$

Figure 9. Trends in the NPD in the study area: $(+)$ positive, $(-)$ negative. The large size of the symbol indicates a significant correlation $(\alpha<0.05)$.

Figure 10. Box-plots for the weather types that were most strongly correlated at each station. (a) NSD and (b) NPD.

Figure 9 shows the spatial distribution of the trends in the NPD in the study area. Only one station showed a significant negative trend during the study period. Figure 10 shows the variability in the temporal trends amongst those stations for which the NPD was more influenced by N and W weather types, and the NSD was more influenced by $\mathrm{C}$, $\mathrm{N}, \mathrm{NW}$ and $\mathrm{W}$ weather types (Figures 5 and 7). This shows that there was no evident associated between the temporal trends in the NPD and the dominant weather type.

Figure 11 shows the spatial pattern of trends in the temporal evolution of the NSD at the study stations. As for the NPD, most of the trends were not statistically significant, with only two stations showing a significant negative trend, and one showing a significant increase in the frequency of the NSD. Figure 10 shows the variability in the temporal trends among those stations more influenced by the $\mathrm{C}, \mathrm{N}$, NW and W weather types (Figure 7).

In general, those stations having the strongest correlation between the NSD and W weather types showed positive coefficients for their temporal trends, whereas the stations more related to the $\mathrm{N}$ and NW weather types had negative coefficients for their temporal evolution. These results are consistent with the decrease and increase in the NW and C weather types, respectively (Table 5), which indicates the temporal trend in the frequency of the various weather types during winter for the main study period (1981-2010) and the two other time slices considered (1961-2013 and 1971-2000). Table 5 shows the absence of significant trends for all weather types except for the NE type, which increased during the 1981-2010 period. Several statistically significant changes were evident during the period 1971-2000, including a significant increase in the A and E weather types, a significant decrease in the SW and W types and a decrease in N, NW and C types.

4.4. The 1961-2013 period: an exploratory analysis of variability in the NSD

To obtain a broader view of the temporal evolution of the 116 NSD we analysed the six available series encompassing 117 the 1961-2013 period. These stations were sufficiently 118 


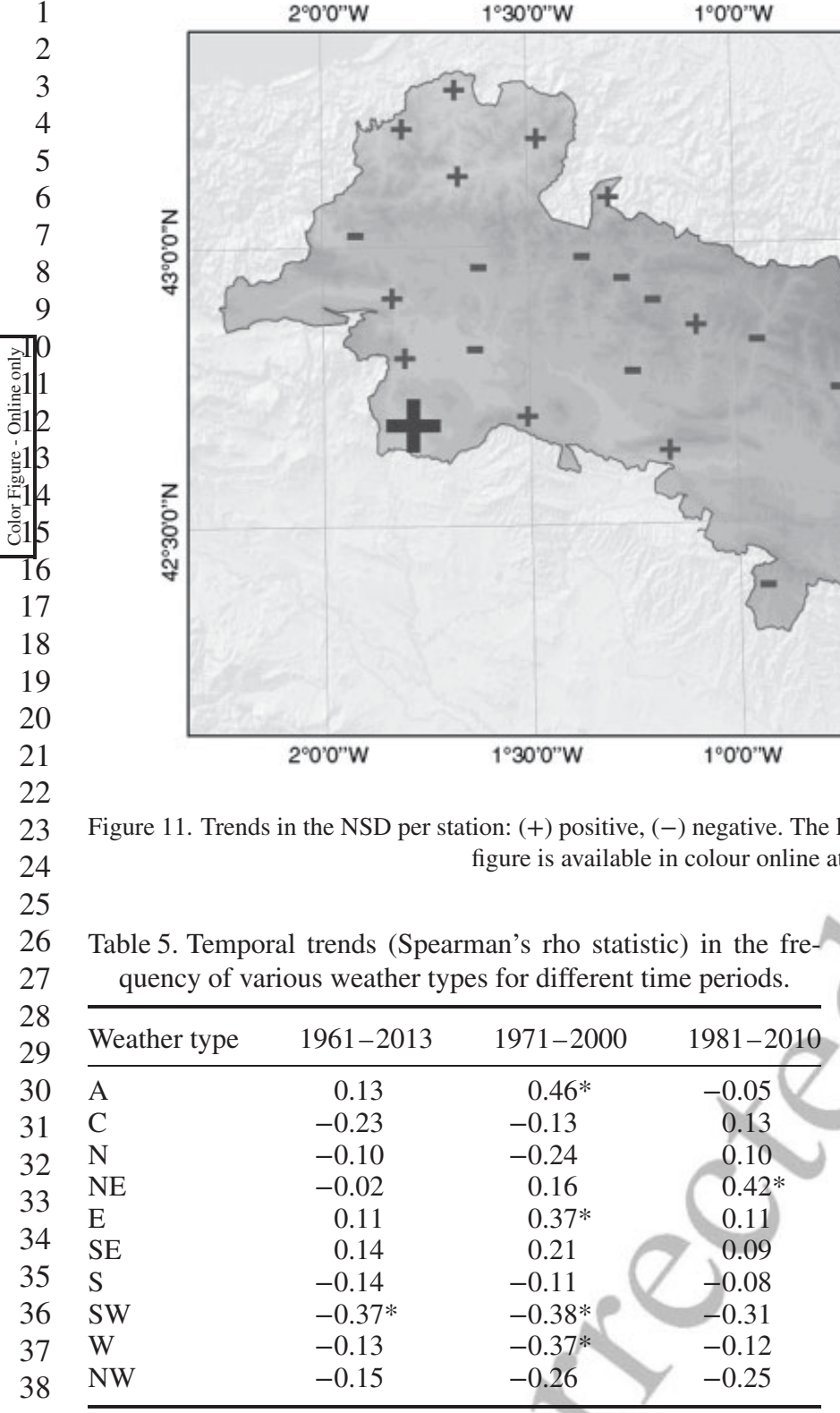

$39 * \alpha<0.05$ e, with winters having abundant snowfall alternat-

Table 6 shows the correlation between stations and weather types for the 1961-2013 period. The A weather type was negatively and significantly correlated at the six stations. The strongest correlations ( 0.01 level of statistical significance) were found for the $\mathrm{W}$ and $\mathrm{NW}$ weather types at all stations except Santesteban. The same level of

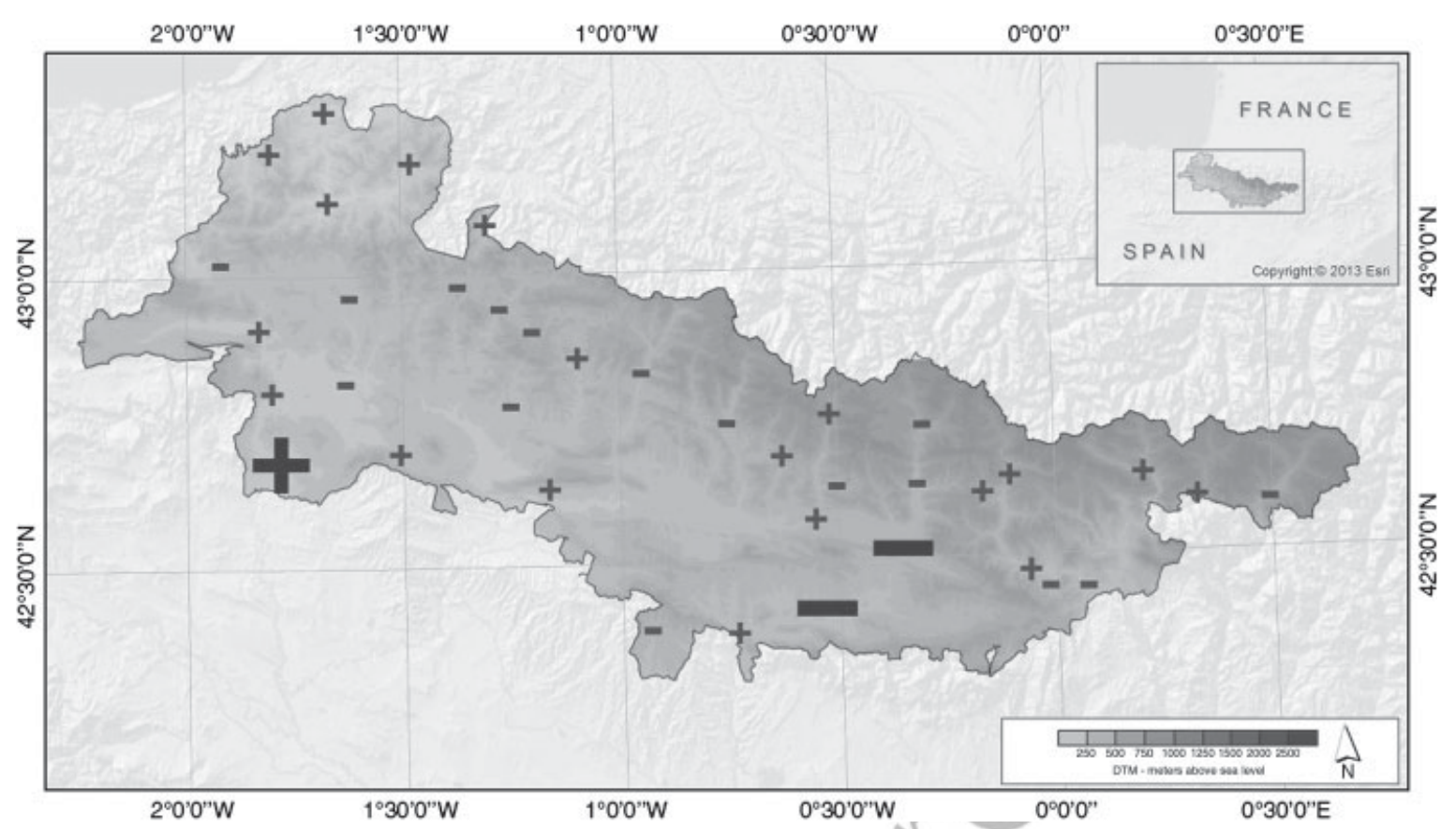

figure is available in colour online at wileyonlinelibrary.com/journal/joc
fic positive, $(-)$ negative. The large size of the symbol indicates a signal

statistical significance was found for the $\mathrm{N}$ weather type for the Abaurrea, Canfranc and Bescos stations, whereas for the most easterly stations (Torla and Pineta) there was a strong correlation with the frequency of the $\mathrm{C}$ weather type. Similar relationships between the NSD and weather types were also found for this set of stations for the 1981-2010 period (Table 6); similar values for Pearson's correlation coefficients were maintained between both periods. As occurred for the period 1971-2000, the western stations were mainly affected by the $\mathrm{N}$ and $\mathrm{NW}$ weather types, and the stations to the east were mainly affected by the NW, W and C weather types. This demonstrates that the results for the period 1981-2010 can be used to accurately reflect the behaviour and variability of snowfall in the study area.

Table 7 shows temporal trends in the NSD for different periods of time: the entire period available (1961-2013); the 1971-2000 period, which is still used as the standard reference period for comparison in many countries; and the most recent period (1981-2010), which was studied in more depth in this study.

Temporal series were tested against a linear time evolution (1981-2010) using the nonparametric Spearman's rank correlation statistic test. Table 7 also reports about the slope of the linear regression in order to illustrate the magnitude of the change.

Depending on the time slice considered, different results were obtained. Thus, the NSD showed a negative trend at all stations during the 1971-2000 period, and it was significant at four stations. After linear fitting the decrease in the NSD per decade at the Pineta station was up to 115 4.9 days decade $^{-1}$. This was consistent with the significant 116 increase in A weather type and the decrease in N, NW, W 117 and $\mathrm{C}$ weather types, as shown in Table 5. However, no 118 
1

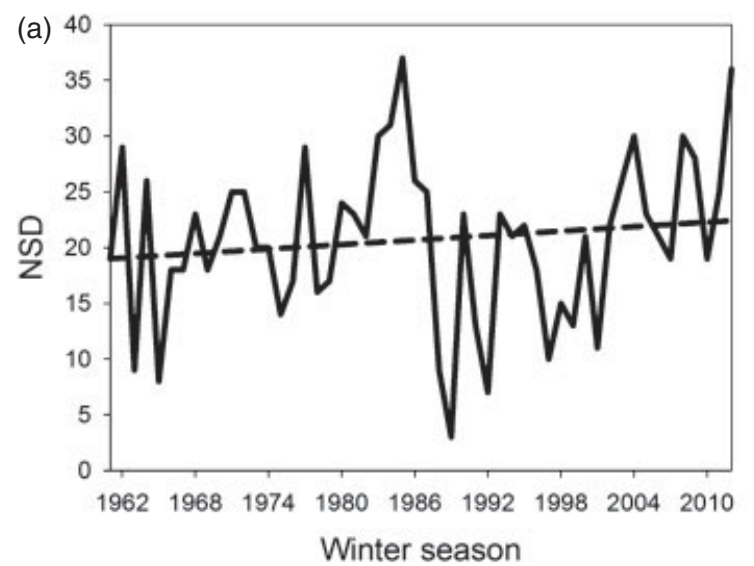

(c)

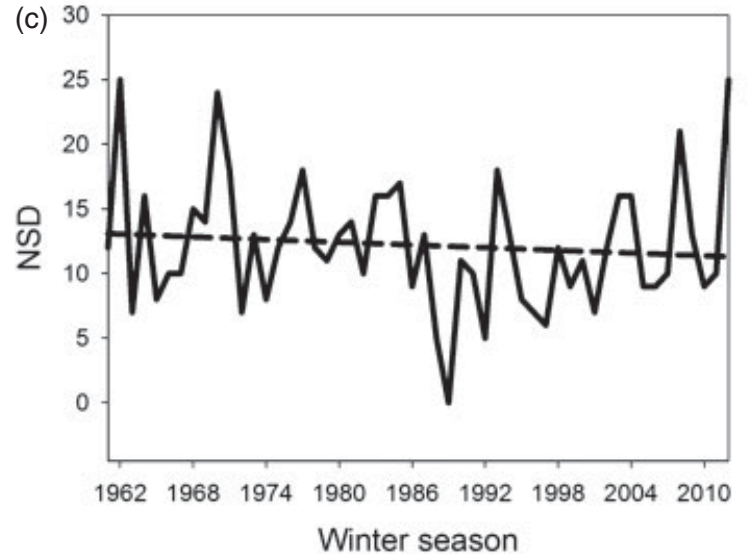

(e)

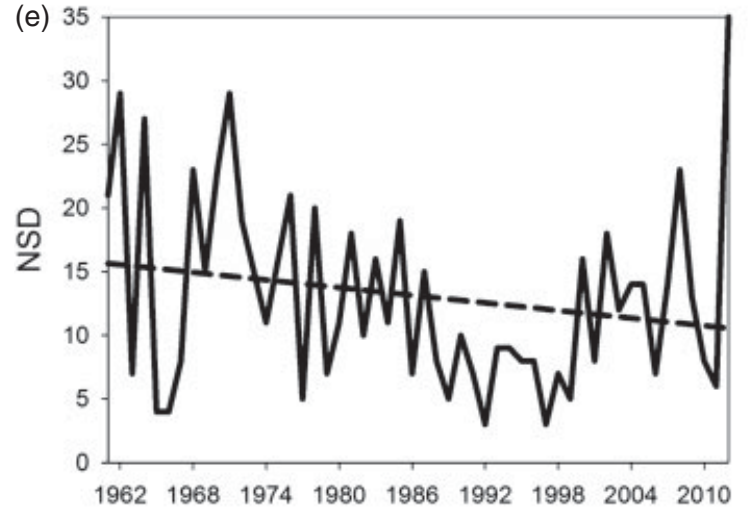

Winter season (b)

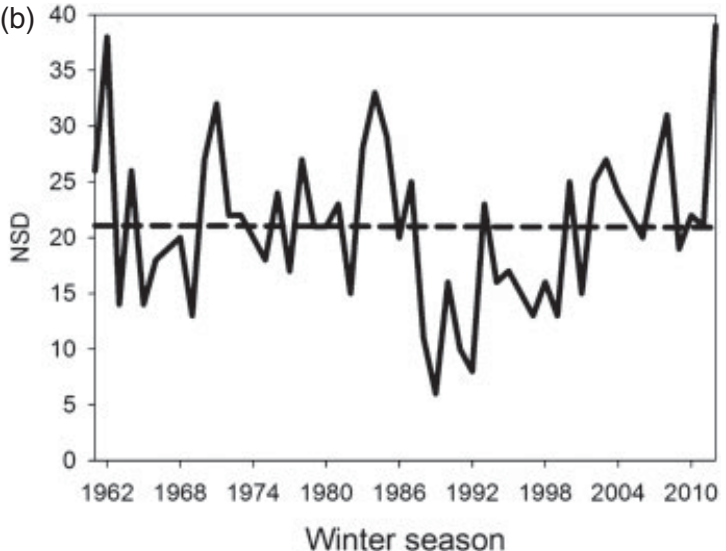

(d) 30
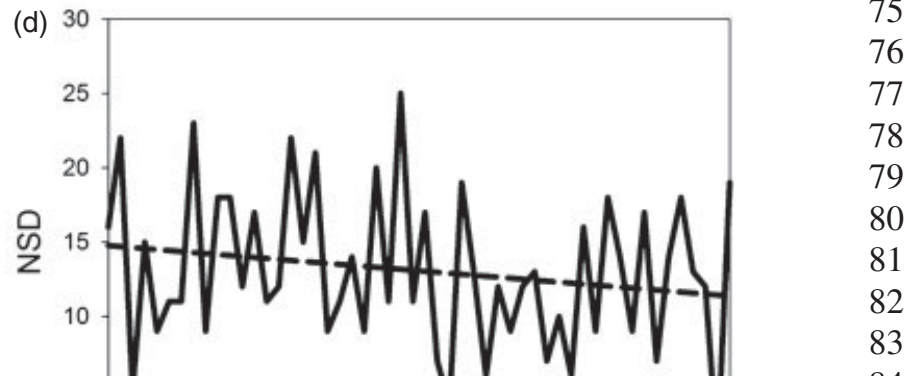

5

$\begin{array}{lllllllll}1962 & 1968 & 1974 & 1980 & 1986 & 1992 & 1998 & 2004 & 2010\end{array}$

Winter season
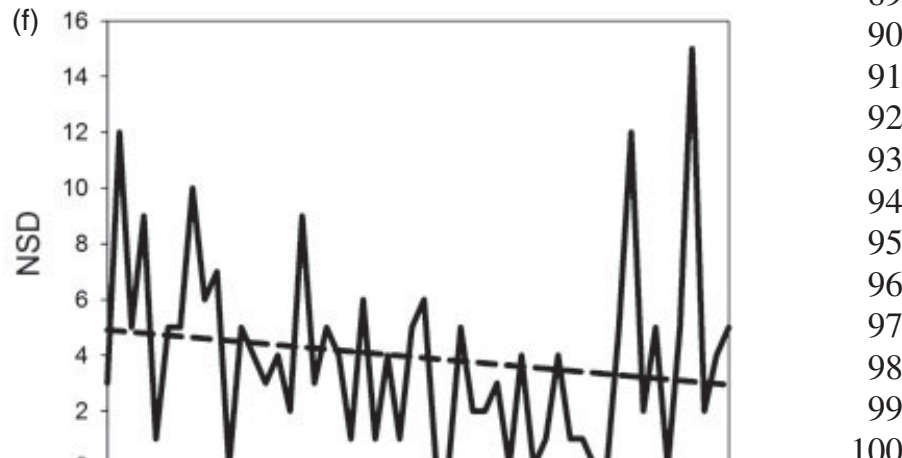

$\begin{array}{llllllllll}1962 & 1968 & 1974 & 1980 & 1986 & 1992 & 1998 & 2004 & 2010 & 101\end{array}$

Winter season

60

61 62 63 64 65

Figure 12. Temporal evolution of the NSD (1961-2013) for selected stations having long climate series and a linear fit to the data. (a) Abaurrea, (b) 104 Canfranc, (c) Bescos, (d) Torla, (e) Pineta and (f) Santesteban.

Table 6. Correlation between stations and weather types for the 1961-2013 (1981-2010) period.

\begin{tabular}{|c|c|c|c|c|c|}
\hline Station & A & $\mathrm{C}$ & $\mathrm{N}$ & $\mathrm{W}$ & NW \\
\hline Abaurrea & $-0.38^{*}\left(-0.45^{* *}\right)$ & $0.23\left(0.38^{*}\right)$ & $0.47 * *(0.59 * *)$ & $0.27 *(0.40 *)$ & $0.40 * *(0.47 * *)$ \\
\hline Canfranc & $-0.43 *(-0.37 *)$ & $0.25(0.17)$ & $0.30 *\left(0.46^{*}\right)$ & $0.37 * *(0.36 *)$ & $0.50 * *(0.59 * *)$ \\
\hline Bescos & $-0.29 *(-0.32)$ & $0.19(0.09)$ & $0.35 *(0.52 * *)$ & $0.31 *(0.24)$ & $0.51 * *(0.54 * *)$ \\
\hline Torla & $-0.49 * *(-0.47 * *)$ & $0.35 * *(0.37 *)$ & $0.14(0.19)$ & $0.57 * *(0.53 * *)$ & $0.48 * *(0.43 *)$ \\
\hline Pineta & $-0.46^{* *}\left(-0.46^{* *}\right)$ & $0.34 *(0.26)$ & $0.19(0.21)$ & $0.37 * *(0.44 *)$ & $0.38 * *(0.55 * *)$ \\
\hline Santesteban & $-0.42 * *(-0.43 *)$ & $0.28 *(0.41 *)$ & $0.18(0.23)$ & $0.06(0.07)$ & $-0.18(-0.14)$ \\
\hline
\end{tabular}


Table 7. Temporal trends (Spearman's rho statistic; $\rho$ ) and slope (s) in the NSD decade ${ }^{-1}$ (linear fit) of the frequencies of NSD for three time periods.

\begin{tabular}{|c|c|c|c|c|c|c|}
\hline \multirow[t]{2}{*}{ Station } & \multicolumn{2}{|c|}{$1971-2000$} & \multicolumn{2}{|c|}{$1981-2010$} & \multicolumn{2}{|c|}{$1961-2013$} \\
\hline & $\rho$ & $\mathrm{s}$ & $\rho$ & $\mathrm{s}$ & $\rho$ & $\mathrm{S}$ \\
\hline Abaurrea & -0.34 & -3.0 & -0.05 & -0.13 & 0.14 & 0.6 \\
\hline Canfranc & $-0.56^{* *}$ & -4.2 & 0.10 & 0.88 & -0.01 & 0.0 \\
\hline Bescos & $-0.36^{*}$ & -1.7 & -0.01 & 0.32 & -0.12 & -0.3 \\
\hline Torla & $-0.43^{*}$ & -2.5 & 0.00 & 0.30 & -0.14 & -0.6 \\
\hline Pineta & $-0.67 * *$ & -4.9 & 0.05 & 0.64 & -0.20 & -0.3 \\
\hline Santesteban & -0.28 & -0.8 & 0.08 & 1.11 & -0.24 & -0.9 \\
\hline
\end{tabular}

$* \alpha<0.05 ; * * \alpha<0.01$.

statistically significant trends were found for any station for the 1981-2010 and 1961-2013 time slices.

\section{Discussion}

In this study we analysed the distribution and temporal evolution of the NSD and the NPD in the Spanish Pyrenees in relation to the frequency of various weather types affecting the Iberian Peninsula.

A key aspect of this work was the creation of a robust database to serve as a starting point for our analyses. Thus, the data for the period 1981-2010 from a dense network of 38 weather stations were analysed, and for 6 stations the data from a longer time slice (1961-2013) were analysed.

The spatial distribution and the temporal evolution of the long-term average NPD and NSD were affected by the interaction between atmospheric flows and the orography of the study area. The average NSD on some locations reaches the $20 \%$ of the total winter days (DJFM). They also show a great interannual variability depending on the prevailing weather types. In some years, snow days in several stations exceeded the $40 \%$ of winter days.

The spatial distribution of the average NPD was predominantly affected by distance to the Atlantic Ocean. However, as the occurrence of snow from precipitation is mostly influenced by elevation, this suggests that temperature is a major factor explaining the number of days of snowfall in this region. However, distance to the ocean markedly influenced the altitudinal gradient of the NSD. Thus, mid-elevation stations (700-1000 ma.s.1.) in the western area had a similar NSD to stations located above $1000 \mathrm{~m}$ a.s.l. in the eastern area. These results suggest that in the west of the study area the greatest influence on the NPD is the frequency of N weather types, which are associated with cold temperatures. In contrast, the W weather type (associated with milder temperature) has a greater influence to the east, where elevations are higher, which may explain why more snowfall days occur at lower elevations. The interannual variability of the NPD increased with elevation and distance to the sea, whereas the NSD was much less variable from 1 year to the next at the highest elevation stations.

The NSD and the NDP were highly dependent on the weather type and frequency during winter. In addition, the weather types varied in their effects in different geographical areas, primarily because of factors including the proximity to the Atlantic Ocean, orographic blocking, elevation and the aspect of the/stations. Previous studies have reported complex interactions between topography and exposure to different air masses, which have led to marked differences in the response of neighbouring areas to synoptic or hemispheric circulation patterns over the Iberian Peninsula (Corte-Real et al., 1998; Goodess and Jones, 2002; Esteban et al., 2005; Vicente-Serrano and López-Moreno, 2006). The Iberian Peninsula is primarily influenced by two types of hemispheric circulation: subtropical highs and extratropical storm tracks that affect northern Europe. In winter the tracks shifts towards the equator. Therefore, the great sensitivity of the frequency of precipitation and snow days at the regional level in the Iberian Peninsula is likely to be mainly because of variations in the strength and frequency of the synoptic weather types affecting this area. With regard to the NPD, the W and $\mathrm{C}$ weather types affected all stations. The NW type mainly affected stations close to sea, whereas the $\mathrm{N}$ type exclusively affected (very significantly) the western stations. With regard to the NSD, the central Pyrenees were mainly affected by the W and NW weather types, whereas the $\mathrm{N}$ weather type is blocked by the main axis of the mountain range that runs from west to east in this area, and exceeds $3000 \mathrm{~m}$ a.s.l. The NW and $\mathrm{W}$ types are associated with moist air that is not very cold. The $\mathrm{W}$ type is associated with fronts that pass over the entire area, producing precipitation at all stations, and snow at those stations at higher elevations.

This is consistent with several studies reporting that the W and SW types favour the accumulation of snowpack at elevations above $1650 \mathrm{~m}$ a.s.1. (Lopez-Moreno and Vicente-Serrano, 2007). The $\mathrm{N}$ weather type affects only western and mid-elevation stations, where strong correlations were found. The $\mathrm{N}$ flow is associated with less humid and colder air, because part of the flow is continental and passes to the southern side of the Pyrenees; in this area the elevation of the range is $1500-2000 \mathrm{~m}$ a.s.l. The $\mathrm{C}$ weather type was associated with weaker correlations than the other weather types, and was only correlated with low elevation areas, or with mid-elevation areas far from the sea. These areas are either blocked by the terrain, or very cold 116 air is needed as a prerequisite for snowfall. The classical 117 pattern is the incursion of cold polar air from northern 118 
1 Russia, and the subsequent passage of a cyclone from 2 the Atlantic Ocean, covering the Iberian Peninsula. The 3 NSD/NPD ratio only increased significantly with northerly 4 flows, which is expected because colder air is present, and 5 was associated with the $\mathrm{C}$ weather type at some stations 6 for the reason explained above.

7 For high elevation stations several weather types (NW, $8 \mathrm{~W}, \mathrm{~N}$ and $\mathrm{C}$ ) were generally positively correlated with the 9 NSD. This resulted in less variability in the coefficient

of variation because it mainly depends on weather types favouring precipitation, whereas for low elevation stations cold air is needed prior to precipitation and these stations are mainly affected by a single weather type (C).

The strength of the correlation between weather type and the NSD clearly increased with elevation for the NW and $\mathrm{W}$ types, whereas for the $\mathrm{N}$ and $\mathrm{C}$ types there were no significant relationships.

There were no significant trends in the NSD or the NPD over the period 1981-2010; years with abundant snowfall days were followed by years having very few snowfall events. However, an increase (not statistically significant) in the NSD was detected for stations mainly affected by the $\mathrm{C}$ weather type, and a slight decrease was found for stations mainly affected by the NW type. This was associated with a slight increase in the $\mathrm{C}$ weather type and a slight decrease in the NW weather type during the same period.

Using the available set of stations spanning the 1961-2013 period, it was possible to confirm that the correlations between the annual frequency of weather types and the frequency of the NPD and the NSD for the 1981-2010 period are representative of longer time periods. Hence, the 1981-2010 period is sufficiently long to represent the spatial variability of the NPD and the NSD, and their relationships to the frequency of weather types.

In the 1981-2010 period, the anticyclonic weather type was most frequent, with the next most frequent being the N, NW and C types. This observation is consistent with previous studies concerning atmospheric circulation over the Iberian Peninsula in winter (Vicente-Serrano and López-Moreno, 2006; García-Valero et al., 2012). A predominance of these three types is associated with a high frequency of snowfall occurrence.

However, the frequency of winter weather types showed marked decadal yariability in the study region. Thus, the selection of the study period could lead to significant differences when temporal trends are inferred, because climate indicators including the NSD are very sensitive to this effect. Thus, for the period 1971-2000 a significant increase in A weather type and a decrease in the N, W, NW and $\mathrm{C}$ weather types was found. This change in the frequency of weather types during the 1971-2000 period has been related to a positive trend in the North Atlantic Oscillation (NAO) in the same period (Quadrelli et al., 2001; López-Moreno and Vicente-Serrano, 2007); this caused a decrease in snow accumulation in the central Pyrenees (López-Moreno, 2005) and some sectors of the Alps (Marty, 2008). However, in the last decade the evolution of the NAO has varied markedly, moderating the slope of the increasing long-term trend (Vicente-Serrano et al., 2010). Thus, years with little snow, such as the 2010-2011 or 2011-2012 winter seasons may be followed by high snowfall winters as 2009-20010 and 2012-2013, which should not be considered as extreme but rather as normal within the typical variability observed. The absence of robust temporal trends in the occurrence of snowfall days is noteworthy; however, during the 1961-2013 period a decrease (not statistically significant) in the NSD was detected for stations located on central Pyrenees. The negative trend during the 1971-2000 period is consistent with the only previous study on this topic in Spain (Pons et al, 2010).

For the period 1960-2006 the increase in mean winter temperature was moderate low (approximately $\left.0.20^{\circ} \mathrm{C} \mathrm{decade}^{-1}\right)$, unlike in summer trend when a sharper increase occurred $\left(0.35^{\circ} \mathrm{Cdecade}^{-1}\right)$. In line with most of the Northern Hemisphere (Swanson and Tsonis, 2009), winter temperature in the study area has often exhibited negative anomalies compared with the last decade (El Kenawy et al., 2012). Thus, the increase (or even decrease) of temperature during the study period has not been sufficient to produce marked shifts in the solid-liquid phase of the precipitation. The forcing mechanisms that can explain the temperature variability are connected to variations in large-scale atmospheric patterns (El Kenawy et al., 2012). Thus, during the last decade the winter NAO has moderated significantly its positive long-term trend, with an increase in the frequency of years with negative phases (Vicente-Serrano et al., 2010), which lead to a higher frequency of weather types associated with high NSD and NPD (NW, W, C, N) in the study area. This result is consistent with the variability of weather types and correlation with NSD and NPD.

During the last decade a slight decrease of winter temperature and a trend reversal on snow indicators such as NSD have been also detected in the Swiss Alps (Scherrer et al., 2013), which suggests the importance of the decadal variability of the climate that often is superimposed to the climate change signal (Díaz et al., 2001; Easterling and Wehner, 2009).

Other studies conducted in other geographic areas or that they not included the last years have reported stronger signal in the increase of the mean winter temperature, and they have shown significant shift on snowfall-total precipitation ratio (Laternser and Schneebeli, 2003; Knowles et al., 2006; Marty, 2008; Serquet et al., 2011).

Finally, this study is consistent with earlier studies such as Maris et al. (2009) where precipitation trends are not significant in the French Pyrenees and the negative trend on NSD during the 1971-2000 period in Northern Spain (Pons et al, 2010).

\section{Conclusions}

The numbers of precipitation and snow days are indicators of climate variability very little used. Our results suggests that the spatial distribution and temporal evolution of the NSD and the NPD in the Spanish Pyrenees are intimately 
1 linked to the variability in the frequency of weather types 2 affecting the Iberian Peninsula. In general, years with high 3 frequency of west (W), northwest (NW) and cyclonic (C) 4 weather systems led to a high NPD. For the NSD there 5 was a gradient from the Western Pyrenees to eastern areas, 6 mainly explained by the frequency of $\mathrm{N}$ weather types 7 in the former area, and high frequencies of NW and $\mathrm{W}$ 8 weather types associated with the latter.

For most stations there was no significant trend found 10 in the NPD or the NSD for the 1981-2010 period. This 11 lack of statistically significant trend is associated to the 12 low increase of winter temperature along the study period, 13 and not clear shifts in the frequency of the weather types, 14 despite clear decadal oscillations. However, the study 15 period chosen can markedly influence the trends observed, 16 as the results showed a statistically significant decrease 17 in the NSD for the 1971-2000 period, but no significant 18 trends for the 1961-2013 and 1980-2010 periods.
This study suggests that improvements in seasonal forecasting of the dominant synoptic patterns could enable advanced warning of the likelihood of winters having an above or below average NSD and NPD.

Further research is also needed to identify the thresholds in temperature increase that could trigger a decline in the NSD in the study area, particularly in the context of available scenarios for winter temperature in the Pyrenees over the coming decades. Moreover, further research on the duration of snow on the ground and the thickness of the snowpack is also of great interest as it can respond to weather types and changing temperatures in a different manner to NSD.

\section{Acknowledgements}

We thank the Spanish Meteorological State Agency (AEMET) for providing the snow database used in this study, and all the volunteer observers who have recorded data on a daily basis over many years. Special thanks to the student María Hernández Aranda who worked on a preliminary database.

This work was supported by the research projects CGL2011-27536/HID: 'Hidrologia nival en el Pirineo central español: variabilidad espacial, importancia hidrológica y su respuesta a la variabilidad y cambio climático', financed by the Spanish Commission of Science and Technology, and CTTP1/12 'Creación de un modelo de alta resolución espacial para cuantificar la esquiabilidad y la afluencia turística en el Pirineo bajo distintos escenarios de cambio climático', financed by the Comunidad de Trabajo de los Pirineos.

It is also framed within the Programa de Grupos de Investigación financed by the Government of Aragon: group S28 'Climate, water, global change y natural systems'.

\section{References}

Barnett TP, Adam JC, Lettenmaier DP. 2005. Potential impacts of a warming climate on water availability in snow-dominated regions. Nature 438: 303-309, DOI: 10.1038/nature04141.
Beniston M. 2003. Climatic change in mountain regions: a review of possible impacts. Clim. Change 59: 5-31.

Carrivick JL, Brewer TR. 2004. Improving local estimations and regional trends of glacier equilibrium line altitudes. Geogr. Ann. 86a: 67-79, DOI: 10.1111/j.0435-3676.2004.00214.x.

Corte-Real J, Qian B, Xu H. 1998. Regional climate change in Portugal: precipitation variability associated with large-scale atmospheric circulation. Int. J. Climatol. 8: 619-635, DOI: 10.1002/(SICI) 1097-0088(199805)18:6<619::AID-JOC271>3.0.CO;2-T.

Del Barrio G, Creus J, Puigdefábregas J. 1990. Thermal seasonality of the high mountain belts of the Pyrenees Mountain. Res. Dev. 10: $227-233$.

Díaz HF, Hoerling MP, Eischeid JK. 2001. ENSO variability, teleconnections and climate change. Int. J. Climatol. 21: 1845-1862, DOI: 10.1002/joc.631.

Easterling DR, Wehner MF. 2009. Is the climate warming or cooling? Geophys. Res. Lett. 36: L08706, DOI: 10.1029/2009GL037810.

El Kenawy A, López-Moreno JI, Vicente-Serrano SM. 2012. Trend and variability of temperature in northeastern Spain (1920-2006): linkage to atmospheric circulation. Atmos. Res. 106: 159-180, DOI: 10.1016/j.atmosres.2011.12.006.

Esteban P, Jones PD, Martín-Vide J, Mases M. 2005. Atmospheric circulation patterns related to heavy snowfall day in Andorra, Pyrenees. Int. J. Climatol. 25: 319-329, DOI: 10.1002/joc.1103.

García-Ruiz JM, Puigdefabregas J, Creus J. 1986. La acumulación de la nieve en el Pirineo Central y su influencia hidrológica (Snow accumulation in the Central Pyrenees and its hydrological influence). Pirineos 27: $27-72$.

García-Ruiz JM, Beguería S, López-Moreno JI, Lorente A, Seeger M. 2001. Los Recursos Hídricos Superficiales del Pirineo Aragonés y su Evolución Reciente (Surface Water Resources in the Aragonese Pyrenees and Their Recent Evolution). Geoforma: Logroño.

García-Valeró J, Montavez JP, Jerez S, Gómez-Navarro JJ, Lorente-Plazas R, Jiménez GP. 2012. A seasonal study of the atmospheric dynamics over the Iberian Peninsula based on circulation types. Theor. Appl. Climatol. 110: 291-310, DOI: 10.1007/s00704-012-0623-0.

Gonseth C. 2013. Impact of snow variability on the Swiss winter tourism sector: implications in an era of climate change. Clim. Change 119: 307-320, DOI: 10.1007/s10584-013-0718-3.

Goodess CM, Jones PD. 2002. Links between circulation and changes in the characteristics of Iberian rainfall. Int. J. Climatol. 22: 1593-1615, DOI: $10.1002 /$ joc. 810 .

Goodess C, Palutikof JP. 1998. Development of daily rainfall scenarios for southeast Spain using a circulation-type approach to downscaling. Int. J. Climatol. 18: 1051-1083, DOI: 10.1002/(SICI) 1097-0088(199808)18:10<1051::AID-JOC304>3.0.CO;2-1.

Hernandez M, Saz MA, Buisan S. 2011. Análisis de la distribución media del numero de días de nieve y su evolución temporal, 1980-2010 Pirineo Occidental. Master Science Report, University • • of Zaragoza.

Jenkinson AF, Collison P. 1977. An Initial Climatology of Wales over the North Sea, Synoptic. Climatology Branch Memorandum No. 62, Meteorological Office, London.

Jonas T, Geiger F, Jenny H. 2008a. Mortality pattern of the Alpine Chamois: the influence of snowmeteorological factors. Ann. Glaciol. 49: 56-62, DOI: 10.3189/172756408787814735.

Jonas T, Rixen C, Sturm M, Stöckli V. 2008b. How alpine plant growth is linked to snow cover and climate variability. J. Geophys. Res. 113: G03013, DOI: 10.1029/2007JG000680.

Jones PD, Hulme M, Briffa KR. 1993. A comparison of Lamb circulation types with an objective classification scheme. Int. J. Climatol. 13: 655-663, DOI: 10.1002/joc.3370130606.

Knowles N, Dettinger M, Cayan D. 2006. Trends in snowfall versus rainfall for the Western United States. J. Clim. 19: 4545-4559, DOI: 10.1175/JCLI3850.1.

Lamb PJ, Peppler RA. 1987. North Atlantic Oscillation, concept and application. Bull. Am. Meteorol. Soc. 68: 1218-1225.

Lasanta T, Laguna M, Vicente-Serrano SM. 2007. Do tourism-based ski resorts contribute to the homogeneous development of the Mediterranean mountains? A case study in the Central Spanish Pyrenees? Tour. Manage. 28(5): 1326-1339, DOI: 10.1016/j.tourman.2007.01.003.

Laternser M, Schneebeli M. 2003. Long term snow climate trends of the Swiss Alps (1931-99). Int. J. Climatol. 23(7): 733-750, DOI: 10.1002/joc.912.

López-Moreno JI. 2005. Recent variations of snowpack depth in the Central Spanish Pyrenees. Artic Antarct. Alp. Res. 37(2): $253-260$. 
Quadrelli R, Lazzeri M, Cacciamani C, Tibaldi S. 2001. Observed winter Alpine precipitation variability and links with large-scale circulation patterns. Clim. Res. 17: 275-284, DOI: 10.3354/cr017275.

Scherrer SC, Wüthrich C, Croci-Maspoli M, Weingartner R, Appenzeller C. 2013. Snow variability in the Swiss Alps 1864-2009. Int. J. Climatol. 33: 3162-3173, DOI: $10.1002 /$ joc. 3653 .

Scott D, McBoyle G. 2007. Climate change adaptation in the ski industry. Mitig. Adapt. Strateg. Glob. Change 12(8): 1411-1431, DOI 10.1007/s11027-006-9071-4.

Serquet G, Marty C, Dulex J-P, Rebetez M. 2011. Seasonal trends and temperature dependence of the snowfall/precipitation-day ratio in Switzerland. Geophys. Res. Lett. 38(7): L07703, DOI: $10.1029 / 2011 \mathrm{gl} 046976$.

Spellman G. 2000. The application of an objective weather-typing system to the Iberian Peninsula. Weather 55: 375-385, DOI: 10.1002/j.1477-8696.2000.tb04023.x.

Swanson KL, Tsonis AA. 2009. Has the climate recently shifted? Geophys. Res. Lett. 36: L06711, DOI:10:1029/2008GL037022.

Trigo RH, Da Camara JP. 2000. Circulation weather types and their influence on the precipitation regime in Portugal. Int. J. Climatol. 20: 1559-1581, DOI: 10.1002/1097-0088 (20001115)20:13<1559::AID-JOC555>3.0.CO;2-5.

Uhlmann B, Goyette S, Beniston M. 2009. Sensitivity analysis of snow patterns in Swiss ski resorts to shifts in temperature precipitation and humidity under condition of climate change. Int. J. Climatol. 29 1048-1055, DOI: $10.1002 /$ joc. 1786

Vajda A, Tuomenvirta H, Jokinen P. 2012. Observed and future changes of extreme winter events in Europe with implication for road transportation. In Proceedings of SIRWEC 16th International Road Weather Conference, Helsinki, Finland.

Vicente-Serrano S, López-Moreno JI. 2006. Influence of atmospheric circulation at different spatial scales on winter drought variability through a semiarid climatic gradient in Nort-east Spain. Int. J. Climatol. 26(11): 1427-145, DOI: 10.1002/joc.1387.

Wash JE. 1995. Long-term observations and monitoring of the cryosphere. Clim. Change 31: 369-394.

World Meteorological Organization. 1989: Calculation of Monthly and Annual 30-Year Standard Normals. WCDP-No. 10, WMO-TD/No. 341

Pons M, Johnson A, Rosas-Casals M, Sureda B, Jover E. 2012. Modeling
climate change effects on winter ski tourism in Andorra. Clim. Res. 54(3): 197-207, DOI: $10.3354 / \mathrm{cr} 01117$.

60 
IMPORTANT NOTE: Please mark your corrections and answers to these queries directly onto the proof at the relevant place. DO NOT mark your corrections on this query sheet.

\section{Queries from the Copyeditor:}

AQ1. References "Pons et al., 2003; Pons et al. 2010; Vicente-Serrano et al., 2010" have not been included in reference list. Please provide details for the same.

AQ2. We have modified the sentence "On Western United states...". Please confirm if it retains the intended meaning.

AQ3. The citation "Lamb et al. (1987)" (original) has been changed to "Lamb and Peppler (1987)". Please check if appropriate.

AQ4. Please conirm if "NCEP" needs to be spelt out here. If yes, please provide the expansion.

AQ5. Please note that the footnote * has been explained in footnote of Table 2, but it has not been placed in the table. Please check and clarify.

AQ6. References "Hernandez et al. 2011; Pons et al. 2009, 2012" have not been cited in text. Please clarify where they should be cited.

AQ7. Please provide the report number and place for reference "Hernandez et al 2011".

AQ8. Please provide the place of conference for reference "Maris et al 2009".

AQ9. These figure(s) 1, 5, 7, 9,11 has been supplied in color. There is a charge to print the figure(s) in color, however figure(s) will be published in color online free of cost. The first color printed page will be $£ 250$ and each color printed page thereafter will be $£ 150$ (per page). Please confirm if this figure is to be reproduced in (a) color in print, (b) color online only if suitable (at no charge to author) or (c) black and white in both cases (please provide new figure). Color will be invoiced when the article is published in print. For the options (b) and (c), could you kindly identify and make any necessary text amendments that may need to be made in the caption or text with regard to this change. 
(WILEY-BLACKWELL

USING E-ANNOTATION TOOLS FOR ELECTRONIC PROOF CORRECTION

Required software to e-Annotate PDFs: Adobe Acrobat Professional or Adobe Reader (version 7.0 or above). (Note that this document uses screenshots from Adobe Reader $\mathrm{X}$ )

The latest version of Acrobat Reader can be downloaded for free at: http://get.adobe.com/uk/reader/

Once you have Acrobat Reader open on your computer, click on the Comment tab at the right of the toolbar:

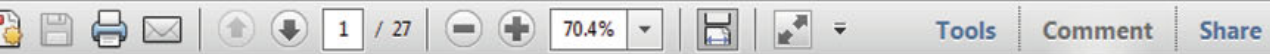

This will open up a panel down the right side of the document. The majority of tools you will use for annotating your proof will be in the Annotations section, pictured opposite. We've picked out some of these tools below:

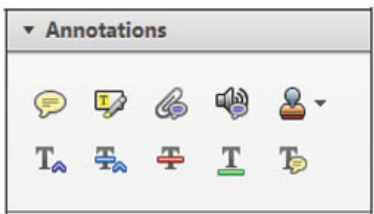

1. Replace (Ins) Tool - for replacing text.

T. Strikes a line through text and opens up a text box where replacement text can be entered.

How to use it

- Highlight a word or sentence.

- Click on the Replace (Ins) icon in the Annotations section.

- Type the replacement text into the blue box that appears.

Idard tramework for the analysis of $\mathrm{m}$ ic) Nevertheless, it alse led to exog، ole of strateg $\cdot \ldots \ldots$ aber of comp 08/06/2011 15:58:17

is that the $\mathbf{s 1}$, which led nain compo level, are ext

exc

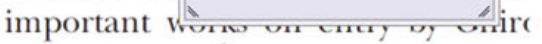
M heneforth) 1 we snen the "hlarl 1

3. Add note to text Tool - for highlighting a section to be changed to bold or italic.

T) Highlights text in yellow and opens up a text box where comments can be entered.

\section{How to use it}

- Highlight the relevant section of text.

- Click on the Add note to text icon in the Annotations section.

- Type instruction on what should be changed regarding the text into the yellow box that appears.

namic responses of mark ups ent with the VAR evidence

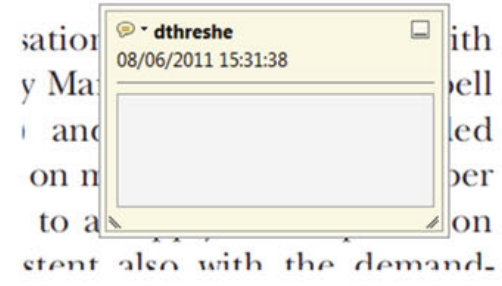

2. Strikethrough (Del) Tool - for deleting text.

Strikes a red line through text that is to be
deleted.

How to use it

- Highlight a word or sentence.

- Click on the Strikethrough (Del) icon in the Annotations section.

there is no room tor extra prohts as : ups are zero and the number of iet) values are not determined by Blanchard and Kiyetaki (1987), sfect competition in general equilil ts of aggregate demand and supply lassical framework assuming monol sen on evorenous number of firme

4. Add sticky note Tool - for making notes at specific points in the text.

Marks a point in the proof where a comment needs to be highlighted.

How to use it

- Click on the Add sticky note icon in the Annotations section.

- Click at the point in the proof where the comment should be inserted.

- Type the comment into the yellow box that appears.

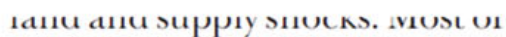

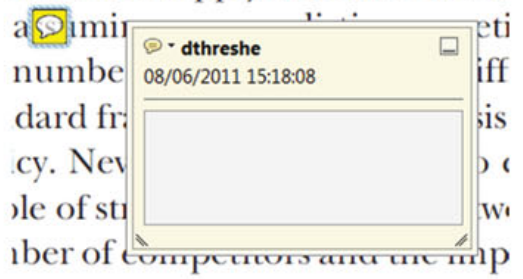

is that the structure of the secte: 


\section{WILEY-BLACKWELL}

\section{USING E-ANNOTATION TOOLS FOR ELECTRONIC PROOF CORRECTION}

5. Attach File Tool - for inserting large amounts of text or replacement figures.

Inserts an icon linking to the attached file in the appropriate pace in the text.

\section{How to use it}

- Click on the Attach File icon in the Annotations section.

- Click on the proof to where you'd like the attached file to be linked.

- Select the file to be attached from your computer or network.

- Select the colour and type of icon that will appear in the proof. Click OK.

E N D

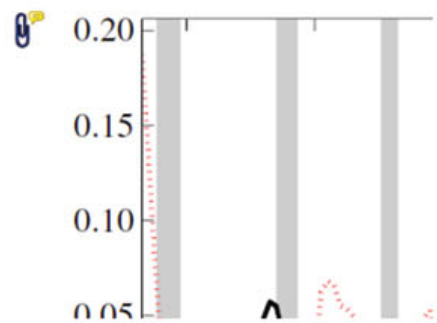

6. Add stamp Tool - for approving a proof if no corrections are required.

8. Inserts a selected stamp onto an appropriate place in the proof.

\section{How to use it}

- Click on the Add stamp icon in the Annotations section.

- Select the stamp you want to use. (The Approved stamp is usually available directly in the menu that appears).

- Click on the proof where you'd like the stamp to appear. (Where a proof is to be approved as it is, this would normally be on the first page).

It the Dusiness cycie, starung with the on perfect competition, constant ret

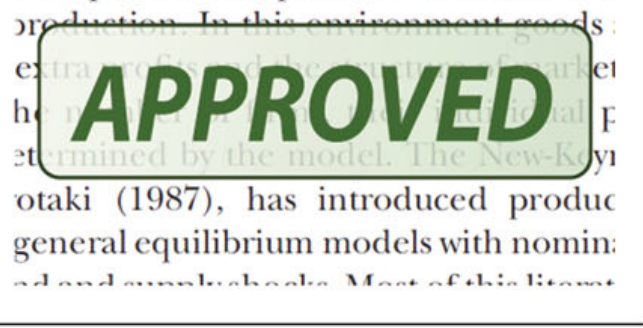

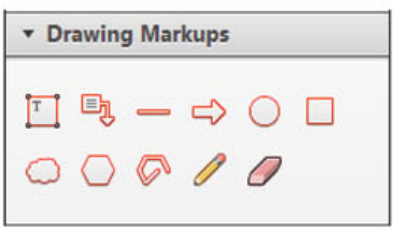

How to use it

- Click on one of the shapes in the Drawing Markups section.

- Click on the proof at the relevant point and draw the selected shape with the cursor.

- To add a comment to the drawn shape, move the cursor over the shape until an arrowhead appears.

- Double click on the shape and type any text in the red box that appears.
7. Drawing Markups Tools - for drawing shapes, lines and freeform annotations on proofs and commenting on these marks.

Allows shapes, lines and freeform annotations to be drawn on proofs and for comment to be made on these marks..

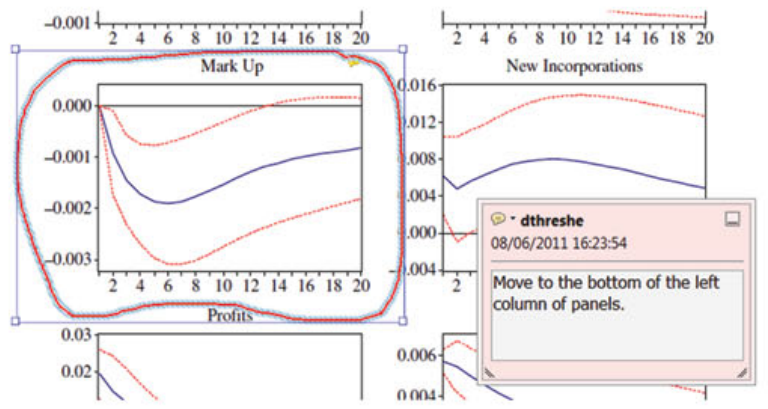

For further information on how to annotate proofs, click on the Help menu to reveal a list of further options:

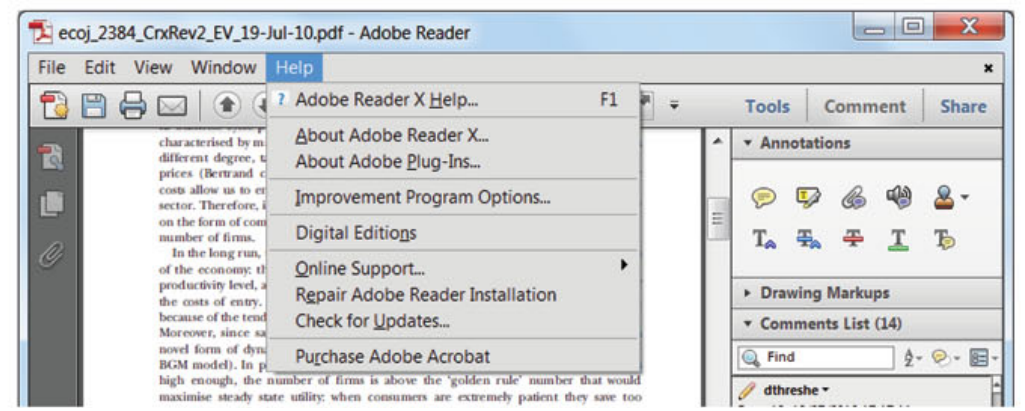

